\title{
Progressive Damage Behaviours of Triaxially Confined Rocks under Multiple Dynamic Loads
}

\author{
K. Liu ${ }^{1,2} \cdot$ J. Zhao $^{1}$
}

Received: 29 August 2020 / Accepted: 13 February 2021 / Published online: 5 May 2021

(c) The Author(s) 2021

\begin{abstract}
Investigation of rock progressive damage under static confinement and strain rates facilitates the generation mechanism of natural fault damage zones. A triaxial Hopkinson bar apparatus is used to perform dynamic triaxial compression tests to examine the damage and degradation process of rocks subjected to multiple impacts. Dynamic mechanical properties are determined under a static triaxial pre-stress of $(30,20,10) \mathrm{MPa}$ and multiple dynamic loadings, with the repetitive impact velocity of $27 \mathrm{~m} / \mathrm{s}$ and strain rates from 50 to 150/s. The acoustic characteristics are identified by ultrasonic measurement to qualify the damage values. The micro-crack parameters, including crack area and volumes are detected using synchrotron $\mathrm{X}$-ray micro-computed tomography $(\mu \mathrm{CT})$ to characterize the progressive damage. In addition, the microcrack orientation, density and fractal dimension are analysed from thin section. Experimental results show that dynamic stress-strain curves can be divided to elastic, nonlinear deformation and unloading phases. Dynamic peak stress, Young's modulus and ultrasonic wave velocity decrease with increasing impact times. The high frequency of ultrasonic wave is filtered by the induced microcracks. The progressive damage and evolution of fracture networks are associated highly with microcrack initiation, propagation, branching and coalescence. Shear bands are commonly generated in granite, and tensile cracks are dominant in marble, while sandstone is mainly failed by compaction and deformation band. The absorbed energy of rock increases nonlinearly with increasing crack surface and volume. Besides, microcracks propagate primarily along the maximum principal stress; the density and fractal dimension exhibit an anisotropic distribution controlled by true triaxial confinement and dynamic impacts.
\end{abstract}

Keywords Triaxial Hopkinson bar · High strain rate loads $\cdot$ Confinement effect $\cdot$ Multiple impacts $\cdot$ Progressive damage

\section{Introduction}

The physical mechanism of fault zones is always a hot topic in recent years, and is identified as the complex result from geological and mechanical factors, intrinsically and extrinsically. The internal structures of large fault zones commonly compose a fault core and the surrounding pulverization damage zones. The fault core consists of highly broken-up fragments or gouge with largest fault displacement, and the associated damage zone contains intense subgrain fracturing with the microns and tens of microns scale

K. Liu

kai.liu@eng.ox.ac.uk

1 Department of Civil Engineering, Monash University, 3800, Monash, VIC, Australia

2 Department of Engineering Science, University of Oxford, Parks Road, Oxford OX1 3PJ, UK
(Aben et al. 2016; Faulkner et al. 2003, 2006; Mitchell et al. 2011; Rodríguez-Escudero et al. 2020; Whearty et al. 2017). The fracturing in fault damage zone affects greatly on the mechanical behaviours [e.g. permeability (Mitchell et al. 2017), anisotropy (Zhao et al. 2011), chemical change and rock-fluid reactions (Goddard and Evans 1995)] of the faults and earthquake dynamic behaviours, including wave propagation, energy dissipation, rupture directivity and destructive efficiency (Aben et al. 2017; Huang et al. 2014). Therefore, understanding the physical mechanism of the fault damage zone is of great importance to seismic events or earthquake prediction and prevention.

Figure 1 summaries a typical diagram of a fault zone (modified from Aben et al. 2016) with the influencing factors and the involved rock dynamic tests. The intrinsic factors generally include the lithology, rock structures and fillings, while the extrinsic factors come from mechanical, seismological, thermal and hydrological effects. Mechanically, the 


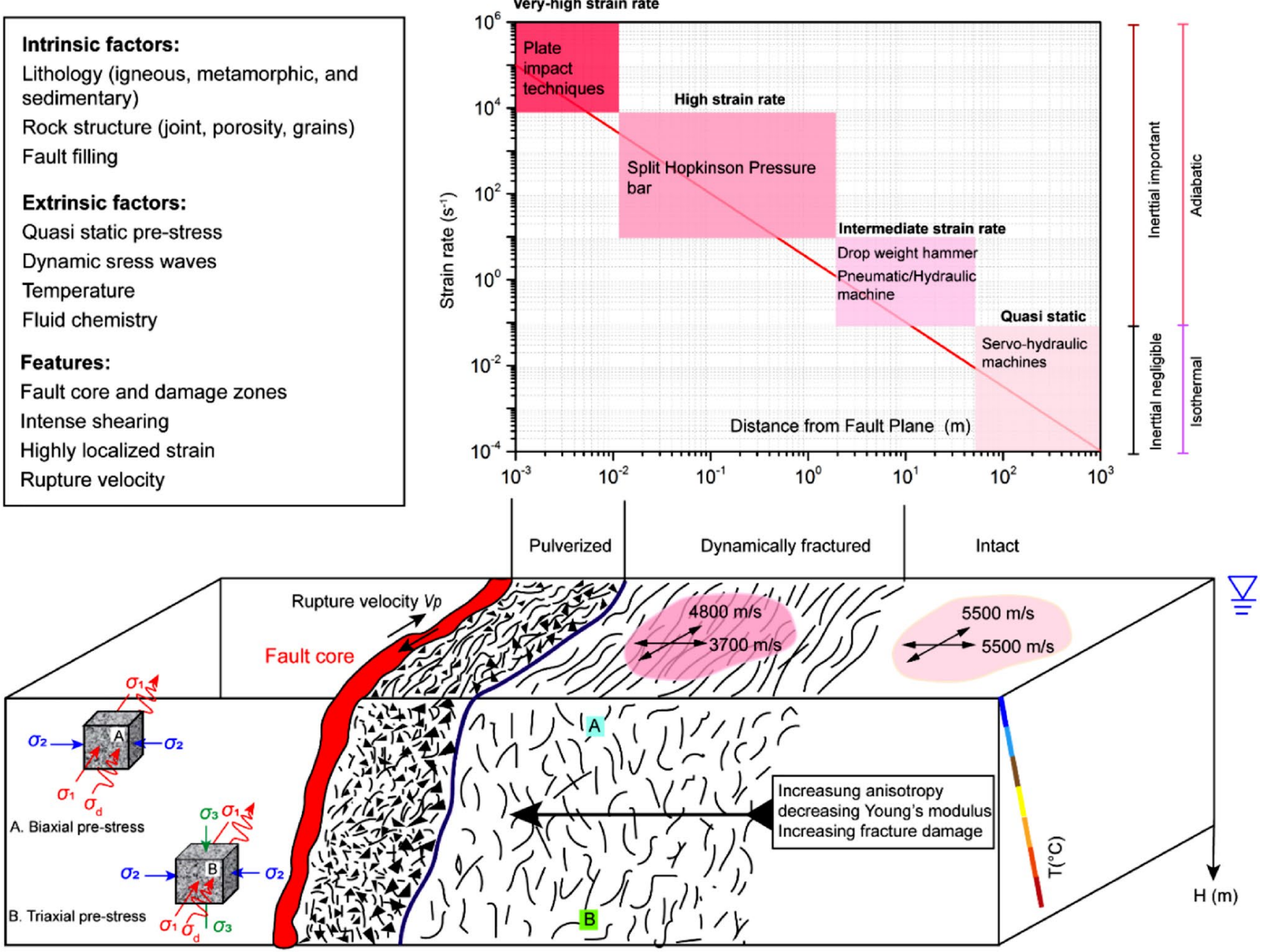

Fig. 1 Typical diagram of a fault zone (modified from Aben et al. 2016), influencing factors and the involved rock dynamic tests

nature pulverized rocks in damage zone, formed by several centimetres to hundreds of meters from the fault core, may experience simultaneously both static and dynamic stress, and even progressively damaged by numerous coseismic loadings (Doan and d'Hour 2012; Doan and Gary 2009; Incel et al. 2019; Mitchell and Faulkner 2009; Wilson et al. 2005; Xu and Ben-Zion 2017; Yuan et al. 2011). From the shallow to deep ground, the fault rocks are generally subjected to quasi-static pre-stress states from biaxial or triaxial confinement conditions. In addition, dynamic loads from earthquakes or remote fault-slip events deform the rocks within a damage zone at a wide range of strain rates from $10^{0}$ to $10^{4} / \mathrm{s}$, depending on the distance to the fault core $(\mathrm{Xu}$ and Ben-Zion 2017). The strain rate distributions of rocks surrounding the fault core (e.g. pulverized, dynamically fractured and intact zones) can be provided by a series of dynamic experimental techniques, such as Split Hopkinson Pressure bar (SHPB) (Hopkinson 1914; Kolsky 1949) and drop weight machine (Liu et al. 2018). Until now, the mechanical behaviour and response of rocks under complex stress conditions are still poorly understood. Therefore, to fully reveal the generation and evolution mechanism of rocks within the damage zone, it is required to submit the rocks to specified quasi-static pre-stress states and high strain rates.

Considerable efforts have been made to investigate the dynamic behaviours of rock at high strain rates using the split Hopkinson pressure bar (SHPB) apparatus. Dynamic uniaxial compressive and tensile strength of rock materials show an increasing trend with strain rate, and fracture modes of rock change from damaged to pulverized states with increasing strain rates (Barber and Griffith 2017; Cai et al. 2007; Dai and Xia 2010; Doan and Gary 2009; Griffith et al. 2018, 2019; Li et al. 2004; Liu et al. 2018; Olsson 1991; Xia et al. 2008; Zhang and Zhao 2014b; Zhu et al. 2015). Effects of confining pressure on dynamic mechanical properties of rocks have also been studied. Dynamic compressive strength of rocks exhibits an obvious confinement dependence under biaxial (Liu et al. 2020a) or triaxial quasistatic 
pre-stress conditions (Frew et al. 2010; Li et al. 2008; Liu and Zhang 2019; Yuan et al. 2011). It decreases with the increasing axial pre-stress along the impact direction, while enhances with the increase of lateral pre-stresses. The confinement dependence has also been observed in dynamic tensile behaviour (e.g. tensile strength, fracture toughness and crack pattern) of rocks under pre-tension (Chen et al. 2016; Zhou et al. 2014) and hydrostatic confinement conditions (Wu et al. 2016). Besides, the dynamic punch shear strength increases with the loading rate and the normal stress (Xu et al. 2019). Under high confining pressure, dynamic failure modes are predominately in shear with a large number of transgranular cracks. It should be noted that, all these studies are on dynamic properties of rock materials that were subjected to a single dynamic load.

However, engineering rock structures or rocks within fault damage zones commonly have experienced numerous coseismic loadings (Aben et al. 2016; Doan and d'Hour 2012; Li et al. 2018), and they are the production of a longterm damage accumulation. Field observations show that progressive accumulation of rock displacement and excavation deformation under successive episodes of dynamic loading should be considered in excavation design (Ma and Brady 1999; Ramulu et al. 2009). Therefore, it is unreasonable to compare directly the field data or observation with the results from single-impact loading experiments. A number of experimental studies have been conducted to study the mechanical behaviour of rocks subjected to multiple impacts. At high strain rates, the progressive damage and failure of rocks subjected to repeated impact loading were investigated using SHPB, and the results show that dynamic stress-strain, elastic modulus, micro-crack evolution and cumulative damage of rocks are highly related to impact energy and numbers (Aben et al. 2016; Braunagel and Griffith 2019; Doan and d'Hour 2012; Li et al. 2004, 2018; Luo et al. 2016; Wu et al. 2014). In addition, with the application of a modified SHPB, the influence of confining pressure on the dynamic weakening behaviour of sandstone under repetitive impacts was studied, and a weakening model considering pressure-dependent energy was proposed (Tong et al. 2019). The mechanical behaviours of rocks subjected to static-dynamic coupled loads greatly differ from that under either static or dynamic loadings ( $\mathrm{Li}$ et al. 2009; Liu et al.
2019, 2020b; Zhu et al. 2012). Therefore, it is necessary to investigate the progressive damage mechanism of rocks subjected to static pre-stress and repetitive impact loading.

This study investigates the progressive failure behaviours of rocks under triaxial pre-stress state and high-rate multiple impacts using a triaxial Hopkinson bar system, which allows to control independently both pre-stress and impact loads. Rock specimens before impact are considered to have a good grain shape without pre-existing micro-cracks. The petrophysical and microstructural studies of impacted rocks are performed to characterize the progressive damages at both macroscopic and microscopic scales. For each impact, the $\mathrm{P}$ and $\mathrm{S}$ wave velocities are measured to evaluate the wave transformation with increasing impact times. The progressive incremental weakening and pulverization of impacted rock are identified by synchrotron X-ray micro-computed tomography $(\mu \mathrm{CT})$. Finally, the induced micro-crack parameters (e.g. orientation, density and fractal dimension) are analysed by an optical microscope. The relationships between the mechanical characteristics, energy consumption and microstructure evolution are discussed, which provides an improved understanding of generation mechanism of rocks within the fault damage zone.

\section{Materials and Methods}

\subsection{Specimen Preparation}

The granite, marble and sandstone materials were selected in this study, corresponding to igneous, metamorphic and sedimentary rocks. These rocks widely occurrence in southwestern China, where earthquakes are frequently caused by the collision of the Indian-Australian and Eurasian. The quasi-static mechanical parameters were determined by uniaxial compression with Instron 600DX machine following the ISRM suggested method. Four specimens of each rock type with a standard size (length $\times$ diameter: $100 \times 50 \mathrm{~mm}$ ) were conducted at a loading rate of $0.2 \mathrm{~mm} / \mathrm{min}$. Brazilian tensile tests were performed using the $300 \mathrm{kN}$ Shimadzu AGS-X Series. The physical and mechanical properties of three rocks are listed in Table 1.

Table 1 The physical and mechanical properties of rock materials

\begin{tabular}{lllllll}
\hline Rock type & Density $\left(\mathrm{kg} / \mathrm{m}^{3}\right)$ & $\begin{array}{l}\text { Young's modu- } \\
\text { lus (GPa) }\end{array}$ & Poisson's ratio & $\begin{array}{l}\text { P-wave velocity } \\
(\mathrm{m} / \mathrm{s})\end{array}$ & $\begin{array}{l}\text { S-wave velocity } \\
(\mathrm{m} / \mathrm{s})\end{array}$ & $\begin{array}{l}\text { UCS (MPa) } \\
\text { Tensile } \\
\text { strength } \\
(\mathrm{MPa})\end{array}$ \\
\hline Granite & 2650 & 48.2 & 0.26 & 4532 & 2801 & 139 \\
Marble & 2800 & 54.4 & 0.21 & 4725 & 2712 & 141.8 \\
Sandstone & 2350 & 9.5 & 0.21 & 2798 & 1860 & 40 \\
\hline
\end{tabular}


The petrographic thin sections were prepared and observed using Zeiss microscope to obtain the microstructural information regarding mineral compositions and grain structures. The photomicrographs of three rocks under cross-polarised light (XPL) are shown in Fig. 2. The granite consists of quartz (45\%), orthoclase (20\%), biotite (15\%), muscovite (10\%), microcline (7\%) and magnetite (3\%). The grain size of granite varies quite significantly between different minerals, with the quartz grains are between 400 and $800 \mu \mathrm{m}$, while orthoclase has grain sizes between $300 \mu \mathrm{m}$ to as large as $1 \mathrm{~mm}$. No existing micro-cracks were found in the granite specimens. The marble is constituted almost purely calcite mineral grains without any impurities, and the grain size varies between 300 and $600 \mu \mathrm{m}$ with no foliation or pre-existing fractures. The sandstone is fine grained, homogeneous and isotropic rock without visible cracks; it comprises quartz (30\%), feldspar (20\%), other accessory minerals (20\%) and matrix (30\%), and the range of mineral size is from 200 to $500 \mu \mathrm{m}$ with an average quartz size of $350 \mu \mathrm{m}$.
For dynamic triaxial compression tests, the specimens were cut from same rock block and polished into the cubes with a size of $50 \times 50 \times 50 \mathrm{~mm}^{3}$. The grinded specimens have a flatness tolerance of $0.02 \mathrm{~mm}$ across the surfaces, and the adjacent surfaces are perpendicular within 0.25 deviation. The specimens are free from visible cracks and are consistent in ultrasonic wave velocities.

\subsection{Test Procedures}

The experimental procedures consist of four steps and are schematically illustrated in Fig. 3. Firstly, the P and S wave velocities of the rock specimen before impact are measured, and the initial state of rock is identified using Synchrotron $\mathrm{X}$-ray $\mu \mathrm{CT}$ scanning for reference. Then, rocks are impacted by a triaxial Hopkinson bar system under a true triaxial confining pre-stress of $(30,20,10) \mathrm{MPa}$ and with the repetitive impact velocity of $27 \mathrm{~m} / \mathrm{s}$ (for granite and marble) or $17 \mathrm{~m} / \mathrm{s}$ (for sandstone). After that, the impacted specimens are measured using both ultrasonic transmission method and

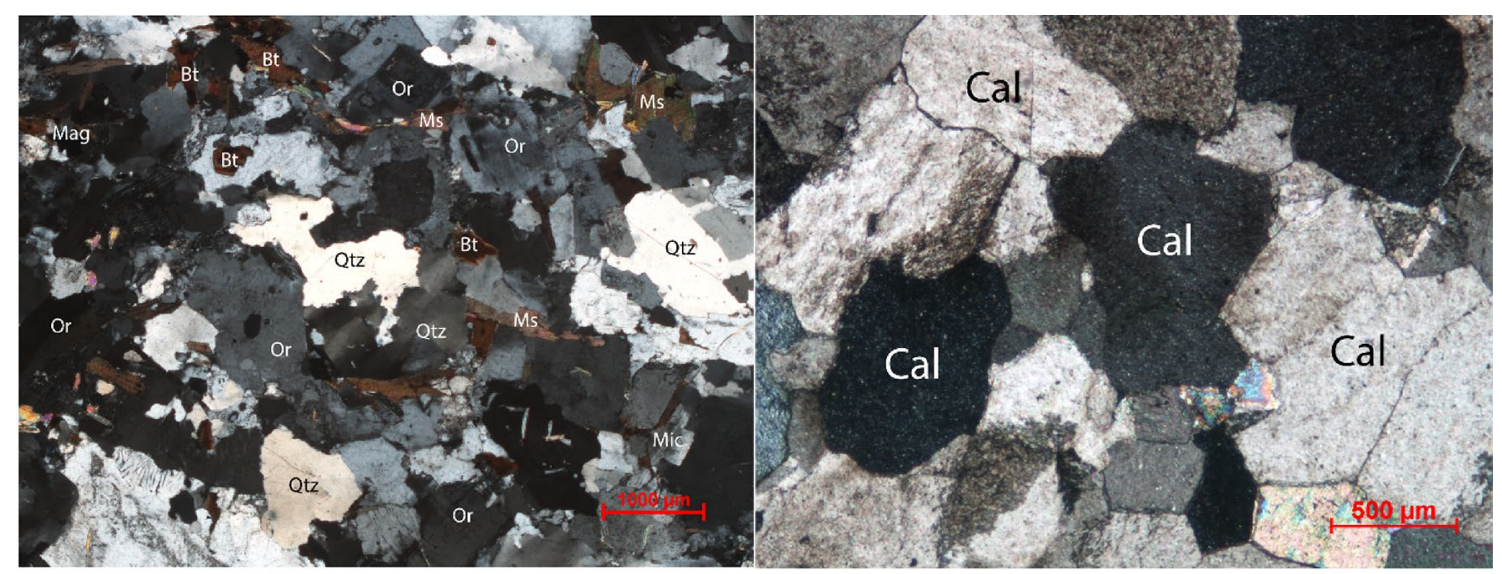

(a)

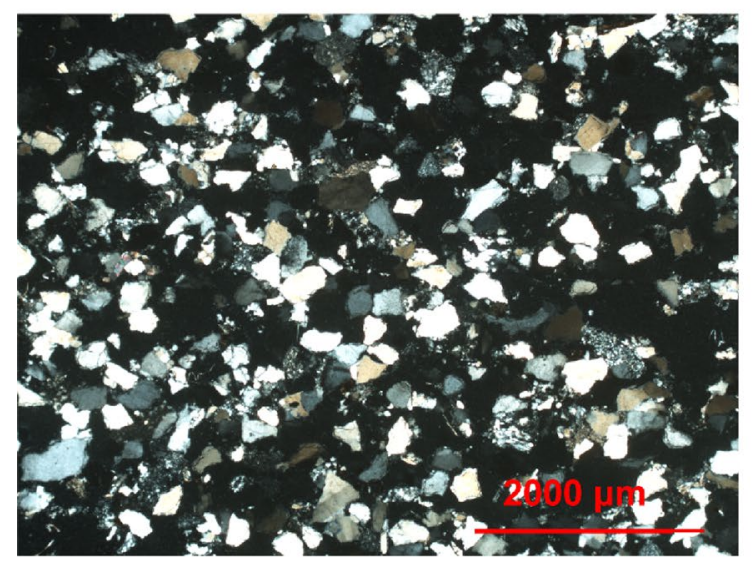

(b)

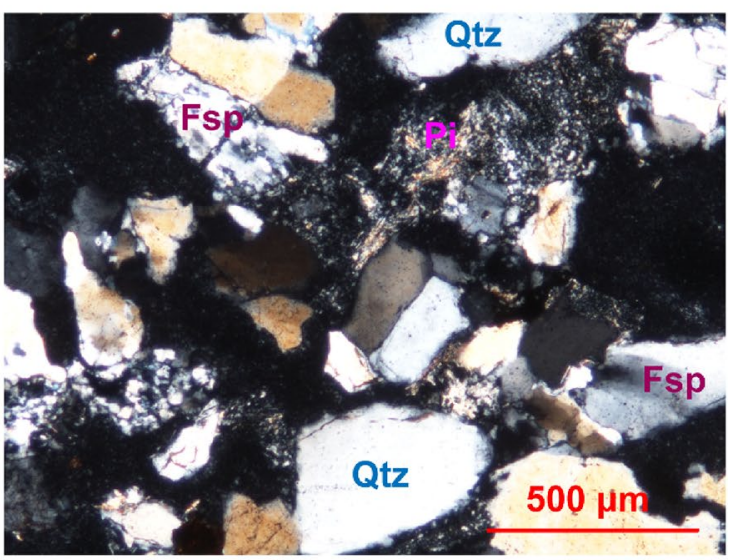

(c)

Fig. 2 Photomicrographs of granite (a), marble (b) and sandstone (c) under cross-polarised light (XPL), Qtz quartz, Or orthoclase, Bt biotite, $M s$ muscovite, Mc microcline, Mag magnetite, Cal calcite, Fsp Feldspar, PI plagioclase 


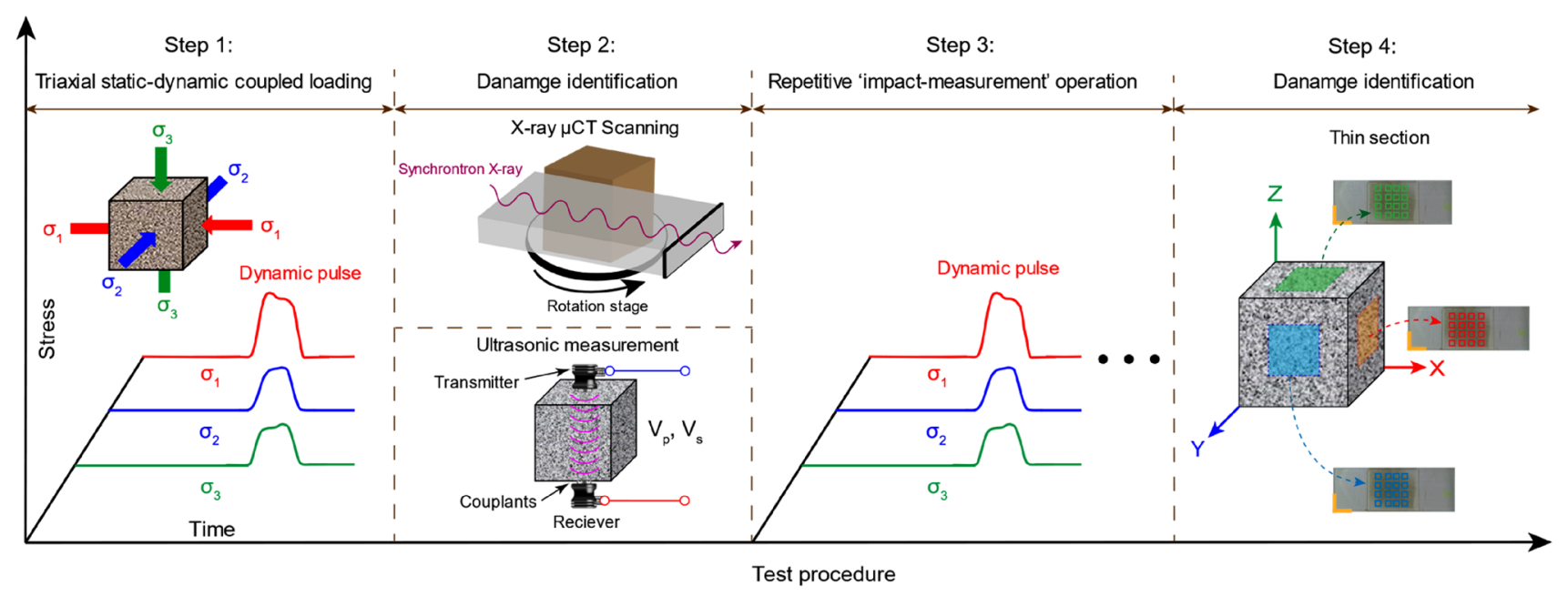

Fig. 3 Schematic test procedures

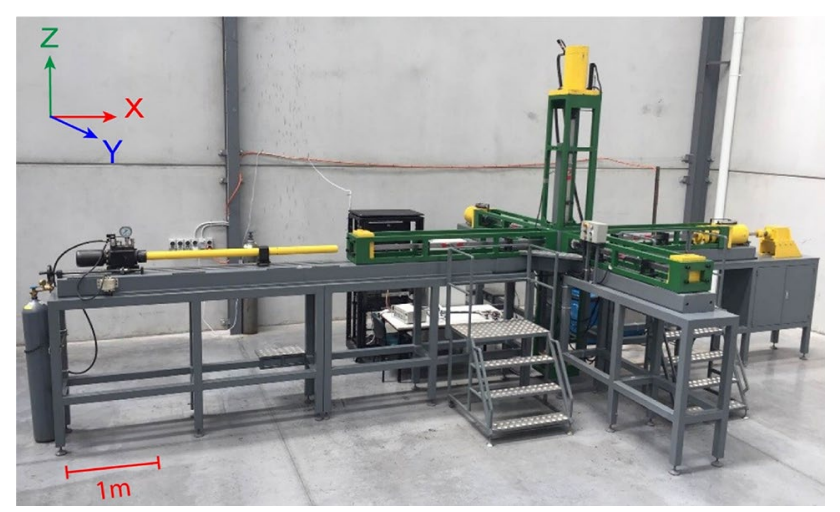

Fig. 4 Triaxial Hopkinson bar system (Liu et al. 2019)

$\mathrm{X}$-ray $\mu \mathrm{CT}$ to quantify the induced damage. The operating process of each specimen is "scan-impact-scan...impactscan" for repetitive rounds until completely failure, which allows for capturing the evolution of fracture network after each cyclical dynamic load. Finally, thin sections of specimen are observed under the ZEISS petrographic microscope and the UV light to extract the crack patterns.

\subsection{Experimental Methods and Measurement Techniques}

\subsubsection{Dynamic Triaxial Compression Configuration}

The dynamic triaxial compression tests were conducted using a triaxial Hopkinson bar apparatus (Fig. 4). It consists of a servo-control hydraulic loading system for quasi-static triaxial confining pressures $\left(\sigma_{\mathrm{x} \text {-static }}, \sigma_{\mathrm{y} \text {-static }}, \sigma_{\mathrm{z} \text {-static }}\right)$ and a dynamic loading system to apply an additional dynamic stress wave on the testing specimen. The apparatus allows the determination of dynamic behaviours of geo-materials under different confinement conditions at high strain rates. Details of the design, operation and calibration of the triaxial Hopkinson bar system are given in the reference (Liu et al. 2019). The experimental setup and loading paths for dynamic repetitive triaxial compression are depicted in the Fig. 5, the rock specimen is initially subjected to a desired triaxial pre-stress state $\left(\sigma_{\mathrm{x} \text {-static }}, \sigma_{\mathrm{y} \text {-static }}, \sigma_{\mathrm{z} \text {-static }}\right)$ or $\left(\sigma_{1}, \sigma_{2}, \sigma_{3}\right)$, and then followed by a dynamic load. As shown in Fig. 5.a, in the test, specimen is sandwiched between the incident bar (2.5 $\mathrm{m}$ in length), transmission bar ( $2 \mathrm{~m}$ in length) along $\mathrm{X}$ direction and four output bars ( $2 \mathrm{~m}$ in length) in $\mathrm{Y}$ and $\mathrm{Z}$ directions. The loading path of rock before impact is shown in Fig. 5b. The quasi-static confinements are achieved independently by the three hydraulic cylinders installed at the end of three pairs of steel square bars in $\mathrm{X}, \mathrm{Y}$ and $\mathrm{Z}$ loading directions, respectively. Dynamic loads are applied by launching a striker ( $\Phi 40 \mathrm{~mm}, 500 \mathrm{~mm}$ in length) in the gas gun impacting on the incident bar, which generates an incident wave towards the specimen. At the location of specimen assembly, the incident wave $\left(\sigma_{\text {In }}\right.$.) is divided into a reflected wave $\left(\sigma_{\mathrm{Re}}\right)$ propagating back into the incident bar, and a transmitted wave $\left(\sigma_{\mathrm{Tr}}\right)$ into the transmission bar. The Poisson's effect induces the lateral expansion of specimen during the impact, thus compressive pulses $\left(\sigma_{\mathrm{y} 1}, \sigma_{\mathrm{y} 2,}, \sigma_{\mathrm{z} 1}\right.$ and $\left.\sigma_{\mathrm{z} 2}\right)$ were generated and transmitted through the $\mathrm{Y}$ and $\mathrm{Z}$ output bars during the dynamic triaxial compression (Fig. 5c). It is worthy to mention that, the compression bars serving as output bars are not only applying confining stresses, but also capturing the variation of confining stresses induced by the Poisson's effect and fracturing of the rock tested.

All square bars are made of high strength maraging 42CrMo steel with a Young's modulus of $210 \mathrm{GPa}$, density of $7850 \mathrm{~kg} / \mathrm{m}^{3}, \mathrm{P}$ wave velocity of $5200 \mathrm{~m} / \mathrm{s}$. The 
Fig. 5 Experimental setup (a) and stress path (b, c)

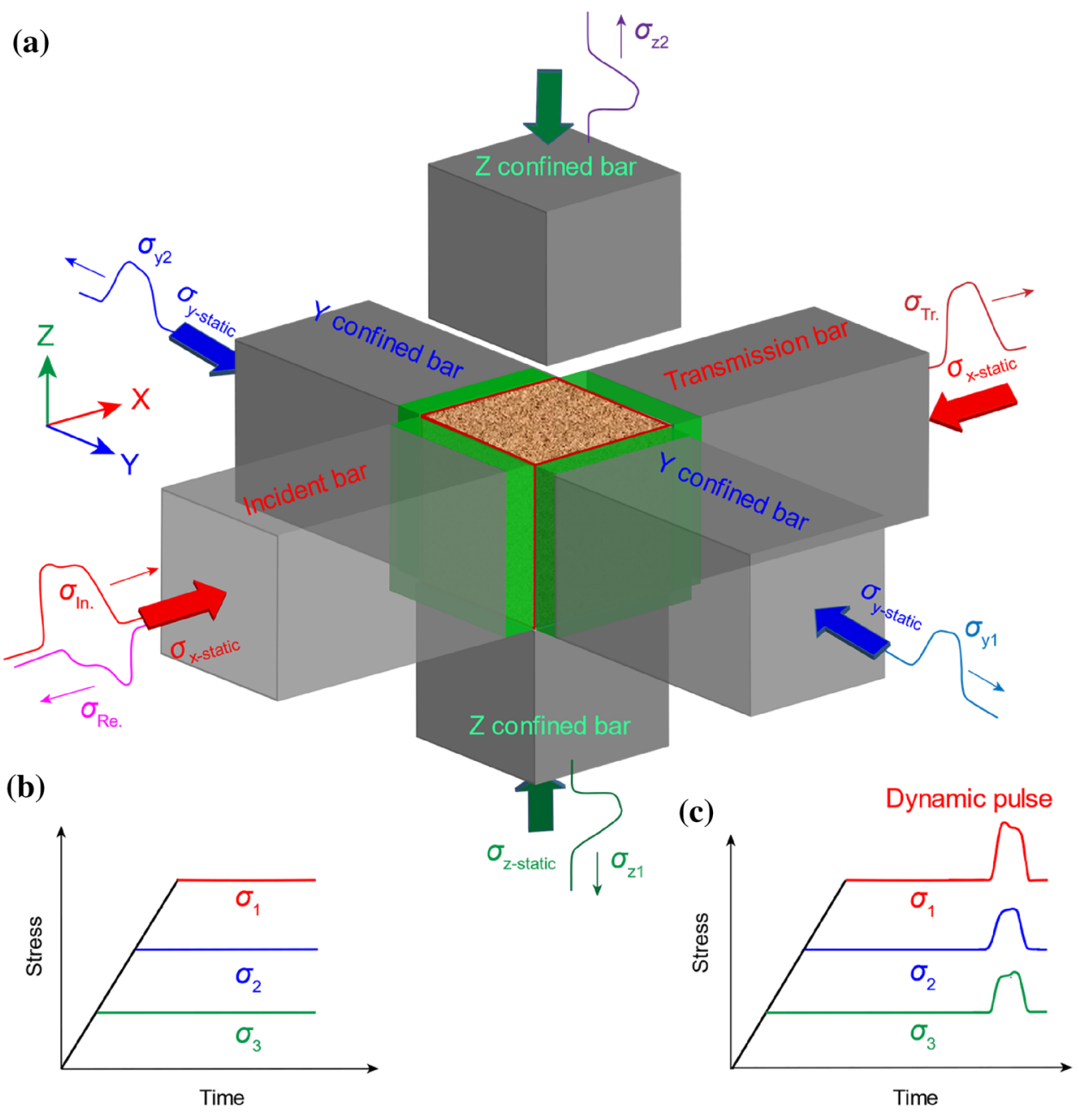

cross-section of square bars is $50 \times 50 \mathrm{~mm}^{2}$. Strain gauges (FLA-6-11) are diametrically mounted on the surfaces of the incident, transmission bars and output bars in $\mathrm{Y}$ and $\mathrm{Z}$ directions. The test signals are recorded at a sampling rate of $1 \mathrm{MHz} / \mathrm{s}$ by strain gauges through Wheatstone bridges and a differential amplifier (SDY-2107A dynamic strain meter). The impact velocity of striker is measured by a laser device right before the impact. Red copper disc with a dimension of $15 \mathrm{~mm} \times 1.5 \mathrm{~mm}$ (diameter $\times$ thickness) is served as the pulse shaper, which produces a wellrepeatability ramped incident wave to reduce high frequency oscillations and wave dispersion effect. The friction between the bar-specimen interfaces are lubricated by petrolatum. The assumptions and data interpretation method for dynamic stress $\left(\sigma_{x}, \sigma_{\mathrm{y}}\right.$ and $\left.\sigma_{\mathrm{z}}\right)$, strain $\left(\varepsilon_{x}, \varepsilon_{\mathrm{y}}\right.$ and $\left.\varepsilon_{\mathrm{z}}\right)$, strain rate $\left(\dot{\varepsilon}_{x}, \dot{\varepsilon}_{y}\right.$ and $\left.\dot{\varepsilon}_{z}\right)$, and volume strain $\left(\varepsilon_{\mathrm{v}}\right)$ in dynamic triaxial compression tests are provided in previous studies (Liu and Zhang 2019; Liu et al. 2019; Xu et al. 2020).
Once the triaxial pre-stress is applied, the strain energy $W_{0}$ stored in the specimen is calculated by:

$W_{0}=(m / 2 \rho E) \sum \sigma_{i}^{2}$

where $\rho, E$ and $m$ are the density, elastic modulus and mass of testing specimen, respectively; $\sigma_{i}$ is the principal prestress applied on the rock.

Based on the one-dimensional elastic wave propagation theory, the elastic strain energies of the incident, reflected and transmission waves within the bars along the $\mathrm{X}$ direction are calculated by Lundberg (1976):

$$
\begin{aligned}
& W_{\text {in }}=\left(A_{\mathrm{b}} C_{\mathrm{b}} / E_{\mathrm{b}}\right) \int_{0}^{t_{0}} \sigma_{\mathrm{in}}^{2} d t, W_{\mathrm{re}}=\left(A_{\mathrm{b}} C_{\mathrm{b}} / E_{\mathrm{b}}\right) \int_{0}^{t_{0}} \\
& \sigma_{\mathrm{re}}^{2} d t, W_{\mathrm{tr}}=\left(A_{\mathrm{b}} C_{\mathrm{b}} / E_{\mathrm{b}}\right) \int_{0}^{t_{0}} \sigma_{\mathrm{tr}}^{2} d t,
\end{aligned}
$$


The output strain energies of induced stress waves along the $\mathrm{Y}$ and $\mathrm{Z}$ directions are expressed as:

$$
\begin{gathered}
W_{\mathrm{y} 1}=\left(A_{\mathrm{b}} C_{\mathrm{b}} / E_{\mathrm{b}}\right) \int_{0}^{t_{0}} \sigma_{\mathrm{y} 1}^{2} d t, W_{y 2}=\left(A_{b} C_{b} / E_{b}\right) \int_{0}^{t_{0}} \sigma_{y 2}^{2} d t, \\
W_{\mathrm{z} 1}=\left(A_{\mathrm{b}} C_{\mathrm{b}} / E_{\mathrm{b}}\right) \int_{0}^{t_{0}} \sigma_{\mathrm{z} 1}^{2} d t, W_{\mathrm{z} 2}=\left(A_{\mathrm{b}} C_{\mathrm{b}} / E_{\mathrm{b}}\right) \int_{0}^{t_{0}} \sigma_{\mathrm{z} 2}^{2} d t
\end{gathered}
$$

where $E_{\mathrm{b}}$ is the elasitc modulus of the bars; $A_{\mathrm{b}}$ is the crosssectional area of the bars; $C_{\mathrm{b}}$ is the longitudinal wave velocity of the bars; $\sigma$ is the stress wave in the bars; $t_{0}$ is the duration of stress wave. $W_{\mathrm{in}}, W_{\mathrm{re}}, W_{\mathrm{tr}}, W_{\mathrm{y} 1}, W_{\mathrm{y} 2}, W_{\mathrm{z} 1}$ and $W_{\mathrm{z} 2}$ correspond to energies carried by the incident, reflected, transmitted waves and output stress waves in $\mathrm{Y}$ and $\mathrm{Z}$ bars, respectively.

The energy absorbed by the specimen $W_{\mathrm{s}}$ is given by:

$W_{\mathrm{s}}=W_{\mathrm{in}}-W_{r e}-W_{t r}-W_{y 1}-W_{y 2}-W_{z 1}-W_{z 2}$

The energy absorption per unit volume of rock specimen is calculated by:

$W_{\text {unit }}=\frac{W_{\mathrm{s}}}{V_{\mathrm{s}}}$

where $V_{s}$ is the volume of rock specimen.

In this study, the dynamic triaxial compression tests on the granite and marble were conducted under a quasi-static true triaxial stress state $\left(\sigma_{\mathrm{x} \text {-static }}, \sigma_{\mathrm{y} \text {-static }}, \sigma_{\mathrm{z} \text {-static }}\right)$ of $(30,20$, 10) $\mathrm{MPa}$ and repetitive dynamic impacts with a striker velocity of $27 \mathrm{~m} / \mathrm{s}$ until failure. The sandstone is initial confined at the same pre-stress state and then followed by successive dynamic impacts with a striker velocity of $17 \mathrm{~m} / \mathrm{s}$. The duration and amplitude of incident waves were kept approximately the same using pulse shapers and controlling the gas pressure in the gas gun. During the dynamic triaxial repetitive impacts, the progressive damage characterization of rock was performed after each impact loading. Microscopic damage was characterized by $\mathrm{P}$ and $\mathrm{S}$ wave velocity, synchrotron X-ray $\mu \mathrm{CT}$ and thin section microphotography.

\subsubsection{Ultrasonic Measurements}

The ultrasonic compressive and shear wave ( $\mathrm{P}$ and $\mathrm{S}$ wave) velocities of rock specimens are measured before and after each impact to quantify the induced damages. The ultrasonic measurement setup consists of four basic components: a waveform generator, two piezoelectric transducers, a signal preamplifier and a data storage/digitizer (Fig. 6a). A rock specimen is sandwiched between two piezometers, with the Olympus Couplant B-Glycerin used at the specimen-piezometer interfaces to improve the contact for efficient sound transmission. A spike-shaped excitation pulse with a duration of $200 \mathrm{~ns}$, produced by the PXI-5412 waveform generator, is sent to the transmitter as the input signal for specimen and is synchronously recorded by the digital storage system. Once the ultrasonic wave travelled through the specimen, it is recognised by the receiver as the output signal and is further amplified by an Olympus preamplifier (Model 5660B). Finally, the amplified signal is collected by a digital storage and digitizer with a sample rate at $f_{\mathrm{s}}=10 \mathrm{MHz}$ to achieve a high enough accuracy (Brantut et al. 2014). This sampling frequency $f_{\mathrm{s}}$ meets the condition of Nyquist-Shannon $\left(f_{\mathrm{s}} \geq\right.$ $f_{\max }$, where $f_{\max }$ is the maximum frequency contained in the spectrum of analogical signal). The $\mathrm{P} / \mathrm{S}$ wave transducers
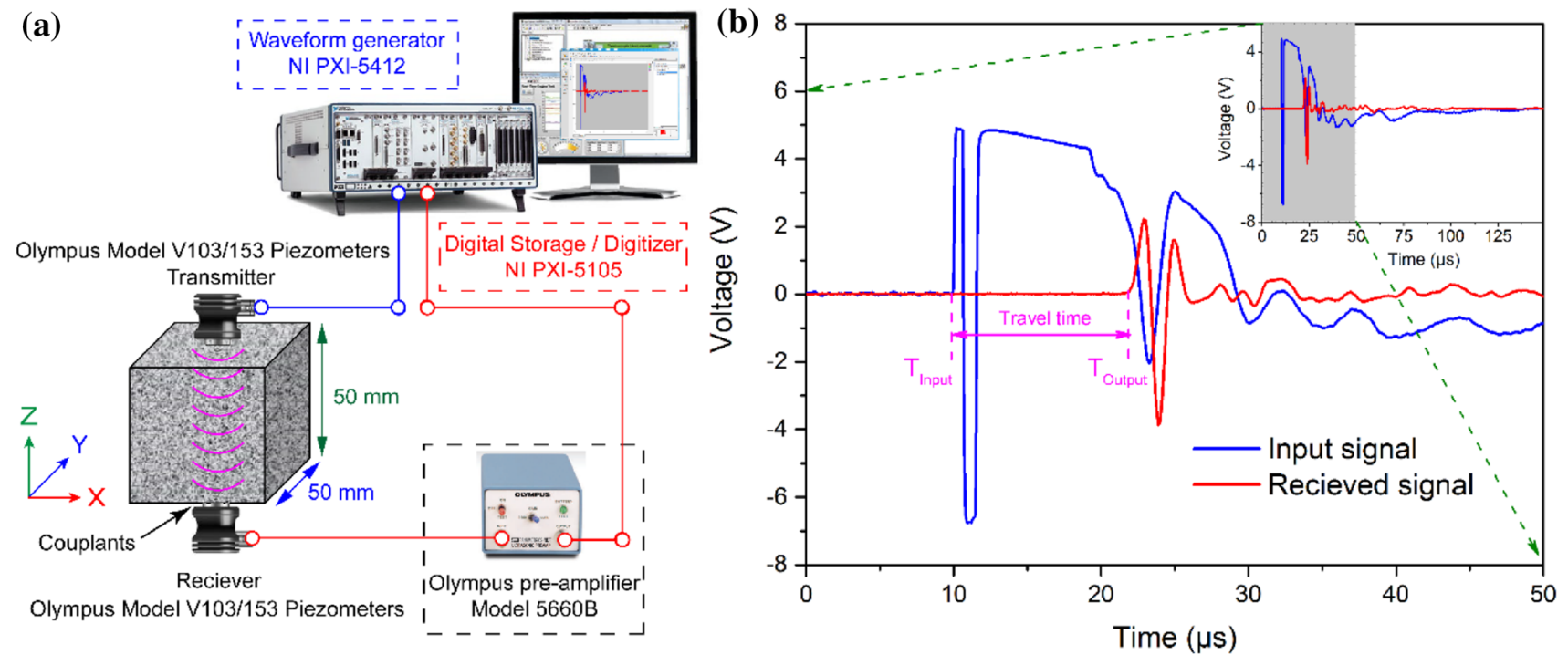

Fig. 6 Measurement of ultrasonic wave velocity. (a) Ultrasonic measurement setup; (b) typical waveforms and the definition of travel time 
used are Olympus Model V103/V153 with a working frequency of $1 \mathrm{MHz}$.

The travel time is generally determined by the time difference of transmitting and receiving moments (Aben et al. 2016). Typical waveforms are shown in Fig. 6b, and the wave velocity $V$ is calculated as follows:

$V=\frac{L_{\mathrm{s}}}{T_{\text {Input }}-T_{\text {Output }}}$

where $L_{\mathrm{s}}$ is the length of testing rock, $T_{\text {Input }}$ and $T_{\text {Output }}$ are time moments of input and output signals, respectively. Both $P$ and $S$ wave velocities of cubic specimen are measured in the $\mathrm{X}, \mathrm{Y}$ and $\mathrm{Z}$ directions for qualifying the anisotropic damages.

\subsubsection{Synchrotron X-ray $\mu \mathrm{CT}$ Identification and Reconstruction}

The mechanical failure of rock is generally associated with complicated progressive failure, as characterized by initiation, propagation, and coalescence of micro-cracks (Bobet and Einstein 1998; Eberhardt et al. 1999). Over the last decade, X-ray $\mu \mathrm{CT}$ has been widely employed to nondestructively identify micro cracks in geo-materials (Cnudde and Boone 2013; Desrues et al. 2010; Johns et al. 1993; Nasseri et al. 2011; Vicente et al. 2017; Zhu et al. 2018). In this study, the damaged specimen after each individual compression was scanned by X-ray $\mu \mathrm{CT}$ using a monochromatic beam available at Australian Synchrotron's Imaging and Medical Beamline (IMBL) (Fig. 7), which provides non-destructive three-dimensional images of fracture network. Damaged rock specimen was digitally scanned with a spatial voxel size of $18.3 \times 18.3 \times 18.3 \mu \mathrm{m}^{3}$, a monochromatic beam of $80 \mathrm{keV}$, an exposure time of $0.5 \mathrm{~s}$ and a specimen-detector distance of $50 \mathrm{~cm}$. Details of X-ray $\mu \mathrm{CT}$ scanning and reconstruction parameters are provided in Table 2. Individual image stacks of the four corner parts of a specimen were stitched together using the Fiji software to reconstruct the whole images in post-processing. Reconstruction of the tomographic data was carried out using the XLI/XTRACT software on the Australian Synchrotron's ASCI supercomputer, which allows a large number of image sets to be reconstructed quickly in a batch mode. All $\mu \mathrm{CT}$ images obtained were further processed using

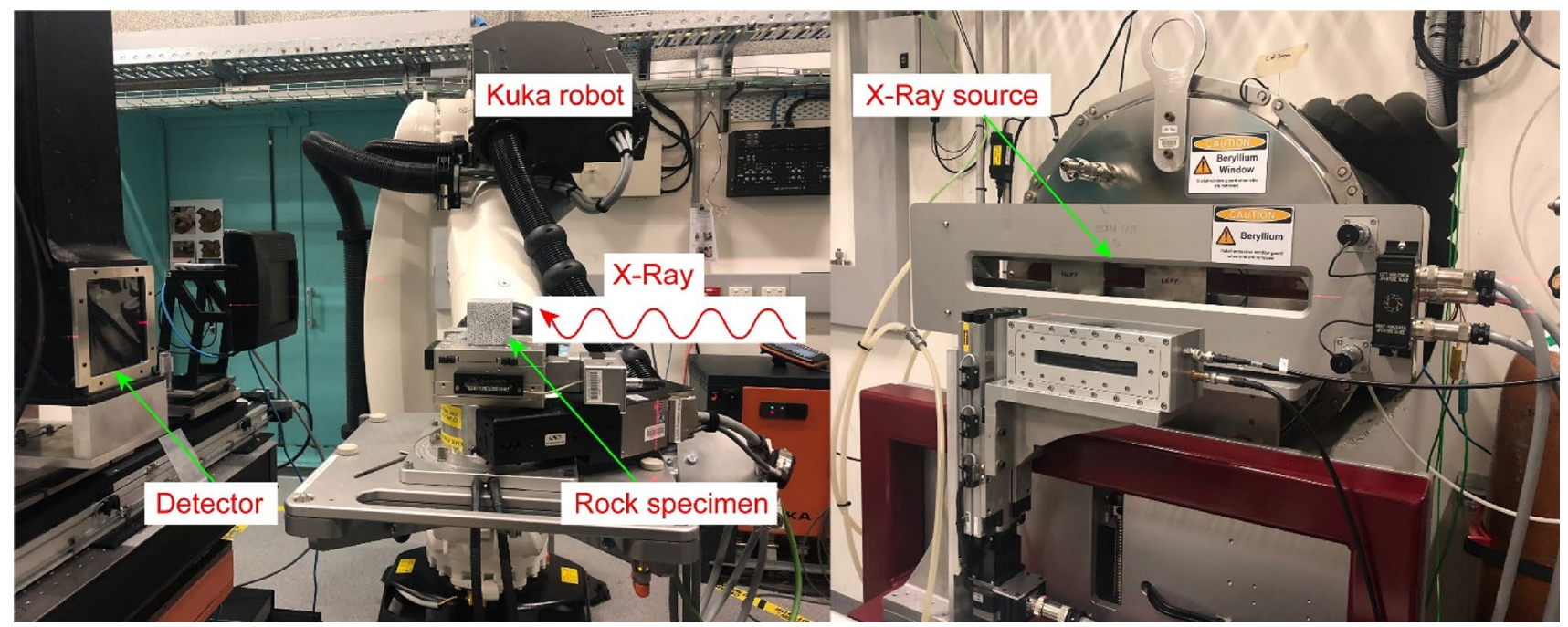

Fig. 7 Rock scanning with synchrotron X-ray micro computed tomography $(\mu \mathrm{CT})$

Table 2 X-ray $\mu \mathrm{CT}$ scanning and reconstruction parameters

\begin{tabular}{lllll}
\hline Scanning & & & Reconstruction \\
\cline { 1 - 2 } \cline { 5 - 6 } Detector & $\begin{array}{l}\text { Ruby camera with } 20 \mu \mathrm{m} \text { screen } \\
\text { and } 105 \mathrm{~mm} / \mathrm{f} 2.8 \text { macro lenses }\end{array}$ & & Reconstruction software & X-tract \\
\hline Spatial resolution & $18.3 \mu \mathrm{m}$ & & Post processing Programme & Avizo 9.5 \\
Source voltage & $80 \mathrm{keV}$ & & Image format & 32 bit tiff \\
Source current & $200.4 \mathrm{~mA}$ & & Ring artefact correction & 17 \\
Exposure time & $0.5 \mathrm{~s}$ & & Filter & Median \\
Specimen-detector distance & $50 \mathrm{~cm}$ & & & $80,000 \mathrm{px}$ \\
Rotation step & $0.1^{\circ}$ & & & \\
\hline
\end{tabular}


the Avizo 9.6 software on the MASSIVE cluster and the MAT$\mathrm{LAB}$ for $2 \mathrm{D}$ analysis. The complexity and interconnectedness of the fracture network, including crack density, direction, surface area, volume and connectivity, are accurately measured for further analysis.

\subsubsection{Microstructural Observations}

Petrographic studies based on thin section microscopic observations provide insights into mineral compositions, rock textures and impact induced cracks. The locations of thin sections are well selected, and the rocks are cut, epoxy solidified and milled in the $\mathrm{X}, \mathrm{Y}$ and $\mathrm{Z}$ direcitons, conresponding to maximum, intermediate and minimum principal stresses, respectively. The standard thickness of a thin section is $\sim 30 \mu \mathrm{m}$, which is adequate for optical observations (Freire-Lista et al. 2016; Homand et al. 2000). Two polarising microscopies used for microscopic examination are Nikon Optiphot2 and Zeiss Axio. The magnifications of the two microscopies are X5, $\mathrm{X} 10, \mathrm{X} 20$ and X40. Both microscopies can work in planepolarised and cross polarised light modes and are equipped with real time cameras. The observation normally starts with $\mathrm{X} 5$ magnification and then tune in higher magnification to observe more details such as micro-cracks. A coordinates adjusting system is mounted on the rotating stage for a precision control of the section position. The mineral composition of the rocks, intergranular and trans-granular macro/micro cracks are distinguished and characterised. Besides, the rose diagram represents the micro-crack orientation and length along specific direction for each plane, which also provides the quantitative analysis for anisotropic damage.

Thin sections were produced from the initial and impacted rock specimens, parallel and perpendicular to the impact direction, respectively. Ideally, evolution of micro-cracks should be studied using a single specimen subjected to successive impact loadings. For rock dynamic tests, a technique for coordinated microscopic examination in a single specimen is not yet available, thus micro-crack evolution was observed in a set of identical specimens cored from the same source block to minimize differences between individual specimens (Tapponnier and Brace 1976). To characterise the spatial evolution of microcracks, quantitative microstructural analysis was performed over a relatively large portion of a crack section when possible to obtain representative results (Moore and Lockner 1995). For each thin section, 20 subregions of $1.1 \times 0.88 \mathrm{~mm}$ located in a thin section were analyzed. Thus, 40 subregions were observed in each dierection of tested specimen, with micro-cracks identified and characterized in the subregions and their lengths measured (Griffiths et al. 2017; Wu et al. 2000).

\section{Test Results}

\subsection{Typical Results Obtained in Dynamic Triaxial Compression}

In a dynamic triaxial compression, rock specimen was firstly subjected to a static triaxial pre-stress and then followed by a dynamic loading. During an individual impact, typical stress waves captured on the bars along X, Y and Z directions are shown in Fig. 8a, in which the cubic granite was tested with the static pre-stress of $(30,20,10) \mathrm{MPa}$ and the impact velocity of $27 \mathrm{~m} / \mathrm{s}$. Note that compression positive is used throughout this article. Using the pulse sharper, the incident $\sigma_{\mathrm{In}}(t)$, reflected $\sigma_{\mathrm{Re}}(t)$ and transmission $\sigma_{\mathrm{Tr}}(t)$ stress waves are well obtained in the impact $X$ direction, while a tensile platform (unloading wave) is observed between the incident and reflected waves, which is different from that of the conventional one-dimensional SHPB tests. It is worthy to mention that the stress value (31.9 MPa), i.e. the offset of reflected wave, equals applied axial pre-stress $\sigma_{\mathrm{x} \text {-static }}(30 \mathrm{MPa}$ ) in the X direction, which have already been confirmed and interpreted in the previous researches (Liu and Zhang 2019; Liu et al. 2019). When impacted in the $X$ direction, the specimen dilated in the lateral $\mathrm{Y}$ and $\mathrm{Z}$ directions due to the Poisson's effect, which induced dynamic stress waves $\left(\sigma_{\mathrm{y} 1}(t), \sigma_{\mathrm{y} 2}(t), \sigma_{\mathrm{z} 1}(t)\right.$ and $\left.\sigma_{\mathrm{z} 2}(t)\right)$ propagating along the output $\mathrm{Y}$ and $\mathrm{Z}$ bars, as observed in Fig. 8a. Thus, the variation of confinement is precisely captured by the strain gauges on the confined bars. This overcomes the limitation of the traditional confined SHPB which could not directly measure the lateral dynamic stresses induced by the axial impact (Christensen et al. 1972; Frew et al. 2010; Li et al. 2008; Lindholm et al. 1972). Specially, the induced dynamic stress waves provide important information on lateral inertial effect, wave transmission as well as the fracturing energy of the testing materials.

The evolution of total stresses $\left(\sigma_{i}(t)=\sigma_{i \text {-static }}+\sigma_{i \text {-dynamic }}(t)\right.$, $i=x, y$ and $z$ ) applied on the specimen is presented in Fig. 8 b. The stress state varies from $(30,20,10) \mathrm{MPa}$ to $(400,60,57) \mathrm{MPa}$ at the peaks with a good synchronicity of three stress components acting on the specimen, indicating that the rock specimen is triaxially compressed by both static and dynamic stress during the impact. Besides, the duration of induced stress waves in $\mathrm{Y}$ and $\mathrm{Z}$ directions is almost equal to that of the incident wave. However, the amplitudes are dependent on the applied pre-stresses, properties of confined bars and the fracturing energy release of rock.

Dynamic stress equilibrium is crucial required to minimize the inertial effects and eliminate the stress gradient across the specimen in the SHPB tests (Ramesh 2008; 


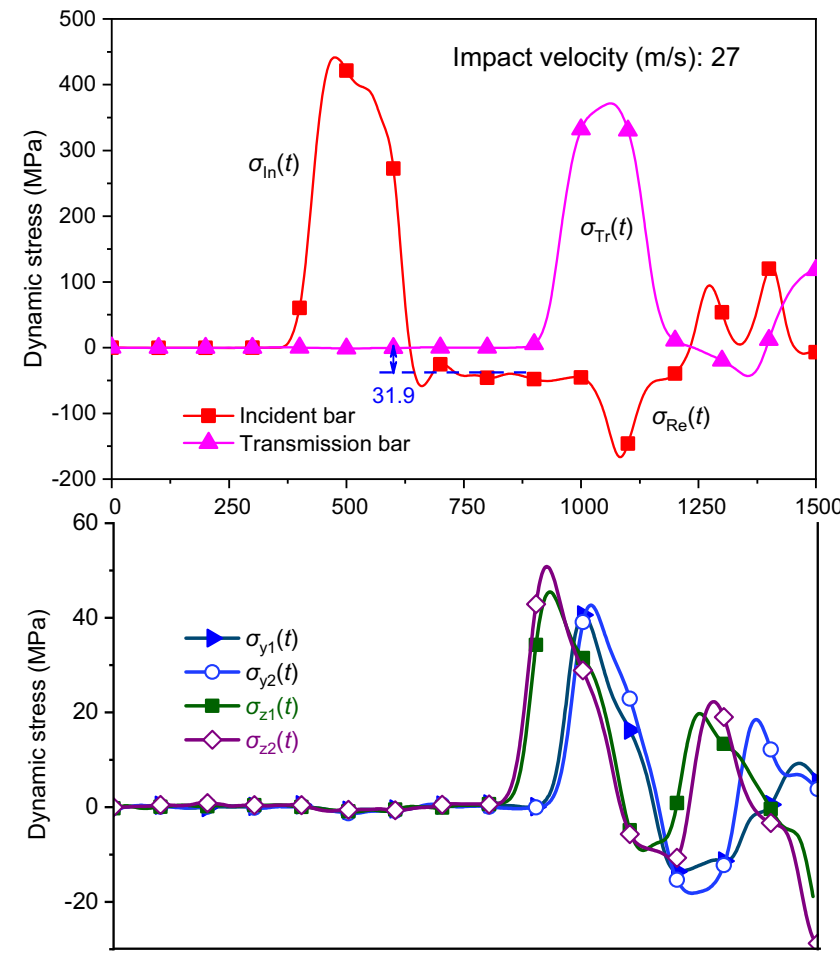

(a)

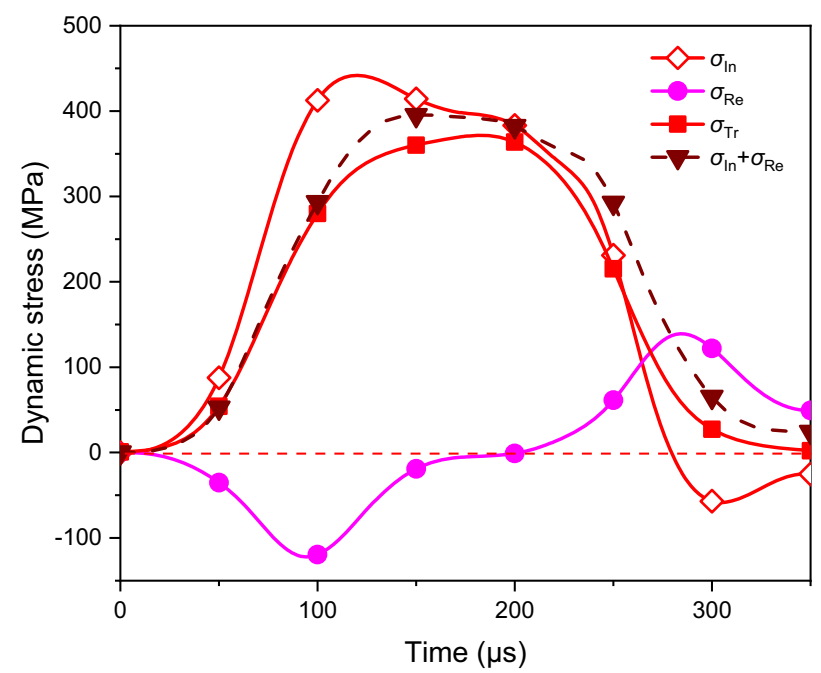

(c)

Fig. 8 Representative experimental data of granite at the impact velocity of $27 \mathrm{~m} / \mathrm{s}$ and a triaxial pre-stress state of $(30,20,10) \mathrm{MPa}$ : a stress waves on the bars along $\mathrm{X}, \mathrm{Y}$ and $\mathrm{Z}$ directions (In incident

Zhou et al. 2012), thus the flow stress of the material could be well determined. The stress equilibrium condition is also affected by the axial unloading wave in the axially constrained triaxial SHPB tests (Chen et al. 2017; Liu and Zhang 2019), thus appropriate positions of strain gauges on the incident bar are carefully selected to obtain

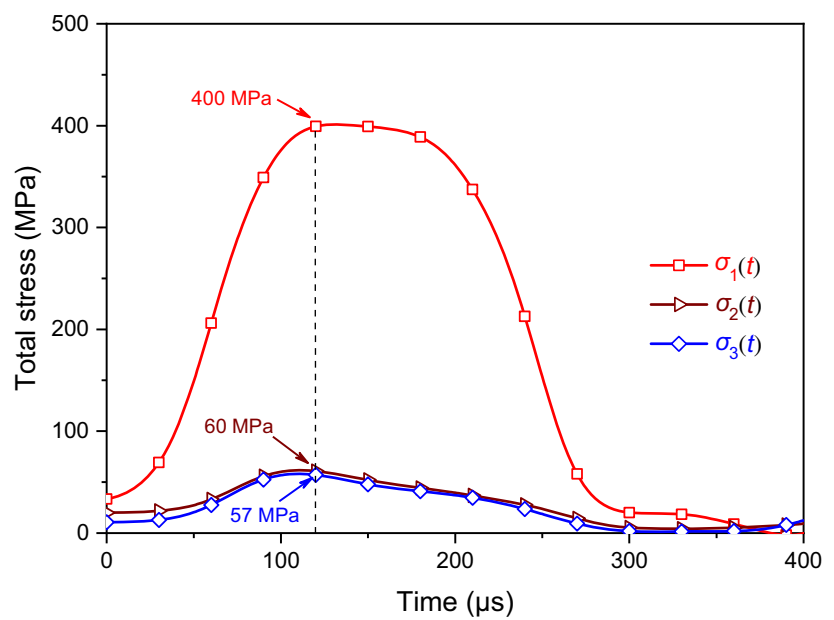

(b)

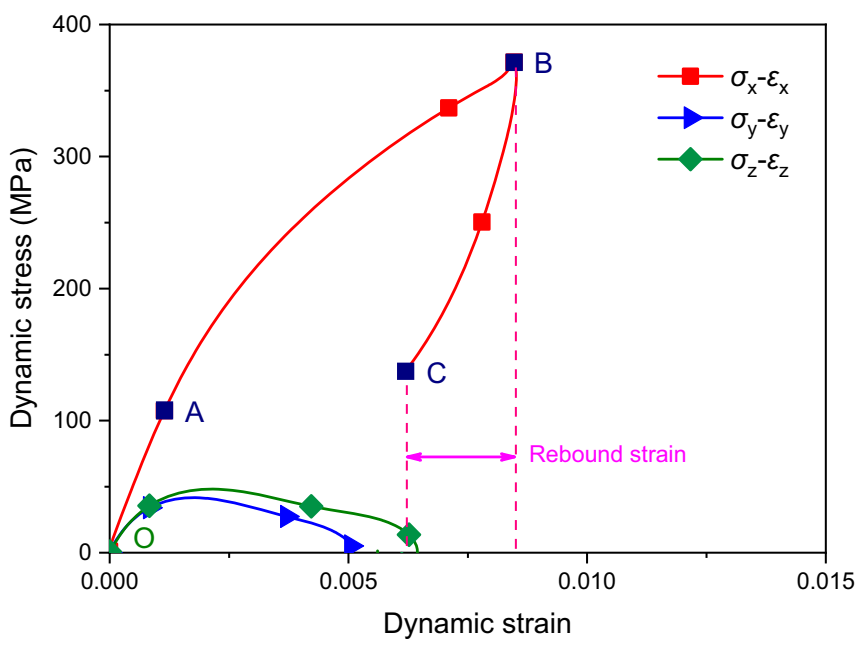

(d)

wave, $R e$ reflected wave, $\operatorname{Tr}$ transmitted wave); b total stress evolution on the specimen; $\mathbf{c}$ stress balance check and $\mathbf{d}$ dynamic stress and strain history in $\mathrm{X}, \mathrm{Y}$ and $\mathrm{Z}$ directions

distinct incident and reflected signals. Besides, the pulsed shaper (i.e. red copper sheet) lengthens the rise time of incident stress wave facilitating the stress of specimen to equilibrate during the time of interest in dynamic triaxial compression tests. As shown in Fig. 8c, and the stress and strain history curves in three directions are finally 
obtained. During the impact, the rock specimen is compressed in $\mathrm{X}$ direction but expands in $\mathrm{Y}$ and $\mathrm{Z}$ direction, and the expansion amount depends on the pre-stresses and dynamic confining stresses. After the impact, there are also residual deformations in $\mathrm{Y}$ and $\mathrm{Z}$ direction. The ratio between $\mathrm{Y} / \mathrm{Z}$ residual deformations and $\mathrm{X}$ deformation is close to Poisson's ratio.

Three stages of dynamic stress-strain curve of rock in the $\mathrm{X}$ direction are observed, as shown in Fig. 8d. The first stage is $\mathrm{OA}$, and it represents the region in which rock deformed quasi-elastically with increasing applied stress. No compaction stage is observed here because the pores and microcracks of the rock are compacted by the initial pre-stress. In the stage $\mathrm{AB}$, rock specimen exhibited a nonlinear deformation, corresponding to an overall decrease in stiffness due to the micro-crack growth and damage accumulation. The stress value at point $\mathrm{C}$ indicates the maximum dynamic stress that the rock specimen experienced during the impact. Stage BC represents the unloading phase, in which the strain decreases due to a rebound effect. The rebound of strain was caused by the release of elastic deformation energy, as the rock specimen still possessed a certain bearing capacity although it is damaged due to the impact (Li et al. 2018).

The summary of dynamic triaxial compression on granite, marble and sandstone are listed in Table 3.

\subsection{Dynamic Stress-Strain History}

The dynamic stress-strain curves of granite subjected to 10 impact times are shown in Fig. 9, with the pre-stress state of $(30,20,10) \mathrm{MPa}$ and impact velocity of $27 \mathrm{~m} / \mathrm{s}$. In Fig. 9a, the general characteristics of stress-strain curves from the first 6 impacts exhibits no obvious difference as the granite remained intact without macroscopic damage. However, the stress-strain curves change progressively as the damage accumulated with increasing impact times from 8 to 10 . The peak stresses present a decreasing tendency from 375 to $344 \mathrm{MPa}$, while the maximum strains exhibit an increase trend from 0.7 to $1.1 \%$. Besides, the Young's modulus decreases slightly with increasing impact times, which indicates that progressive damage of rock increases with impact times. For the dynamic stress-strain curves in the $\mathrm{Y}$ and $\mathrm{Z}$ directions, as observed in Fig. 9b, both of the maximum stress and strain increase with impact times, indicating that the Poisson's ratio of rock specimen increases with the accumulation of rock damage. It is interesting to find that, for each impact, the peak stress $\sigma_{\mathrm{y}}$ and strain $\varepsilon_{\mathrm{y}}$ in the $\mathrm{Y}$ direction are larger than that in the $\mathrm{Z}$ direction. This is because of the difference of pre-stresses applied on the specimen, i.e., $\sigma_{\mathrm{y} \text {-static }}=20 \mathrm{MPa}$ and $\sigma_{\mathrm{z} \text {-static }}=10 \mathrm{MPa}$. Besides, granite underwent an irreversible deformation when subjected to same incident stress waves. Therefore, with the increase of impact time, residual strains display an increasing trend.

Figure 10 shows dynamic stress-strain curves of marble under the same static-dynamic coupling loading condition as that of granite. Five repetitive impacts were performed on marble from intact to fully failure. It is obvious in Fig. 10a that the marble exhibits a progressive degradation process during the static-dynamic repetitive loadings. The dynamic peak stress decreases $10.5 \%$ from 372 to $333 \mathrm{MPa}$, and the maximum strain increases sharply from 0.49 to $1.03 \%$ with increasing impact times. It should be noted that the marble presents a transition from brittle to plastic deformation with the increase of impact times. This transition is due to the micro-crack propagation and coalescence, which will be further validated by the $\mu \mathrm{CT}$ scanning in the below section. Figure 10.b presents that dynamic stress-strain curves of marble in the $\mathrm{Y}$ and $\mathrm{Z}$ directions, in which the deformation trend is somehow similar to that of granite. The lateral residual deformation increases with impact times, which results in the specimen size expansion in the $\mathrm{Y}$ and $\mathrm{Z}$ directions.

The dynamic stress-strain curves of sandstone subjected to 4 impacts are shown in Fig. 11, with the pre-stress state of $(30,20,10) \mathrm{MPa}$ and the repetitive impact velocity of $17 \mathrm{~m} / \mathrm{s}$. In the impact direction (X direction), the dynamic peak stress drops from 175 to $147 \mathrm{MPa}$ (Fig. 11a), corresponding to a reduction of $16 \%$. The maximum strain increases with impact time while the Young's modulus decreases, which indicates the stiffness degradation of sandstone during the repetitive impact loading. The responses in the lateral Y/Z direction are presented in Fig. 11b. It is important to find out that, during the first three impacts, the peak stress, peak strain and residual strain of specimen in the $\mathrm{Y}$ direction is nearly the same with that in the $\mathrm{Z}$ direction, and they increase with impact times. While they show a different value at the 4th impact, in which the sandstone failed by a macroscopic shear bend.

\subsection{Dynamic Strain Rate Evolution}

The strain rate evolution of three rocks subjected to impact loading under triaxial confinement are presented in Fig. 12. Note that the strain rate here is in the impact direction. Generally, the testing specimen was compressed and unloaded during the impact, which resulted in the positive and negative strain rate stages, respectively. At the loading stages, the strain rate increases smoothly to the positive peak value, and then decreases slowly to a stable platform. After that, it drops sharply to the negative level, which suggests that the release of stored elastic energy in rock during the unloading (Li et al. 2004, 2018). The critical points of positive and negatives strain rates mean the time moment that rocks reach their maximum strain during the impact, and these points delayed with increasing impact times. For granite, as shown 


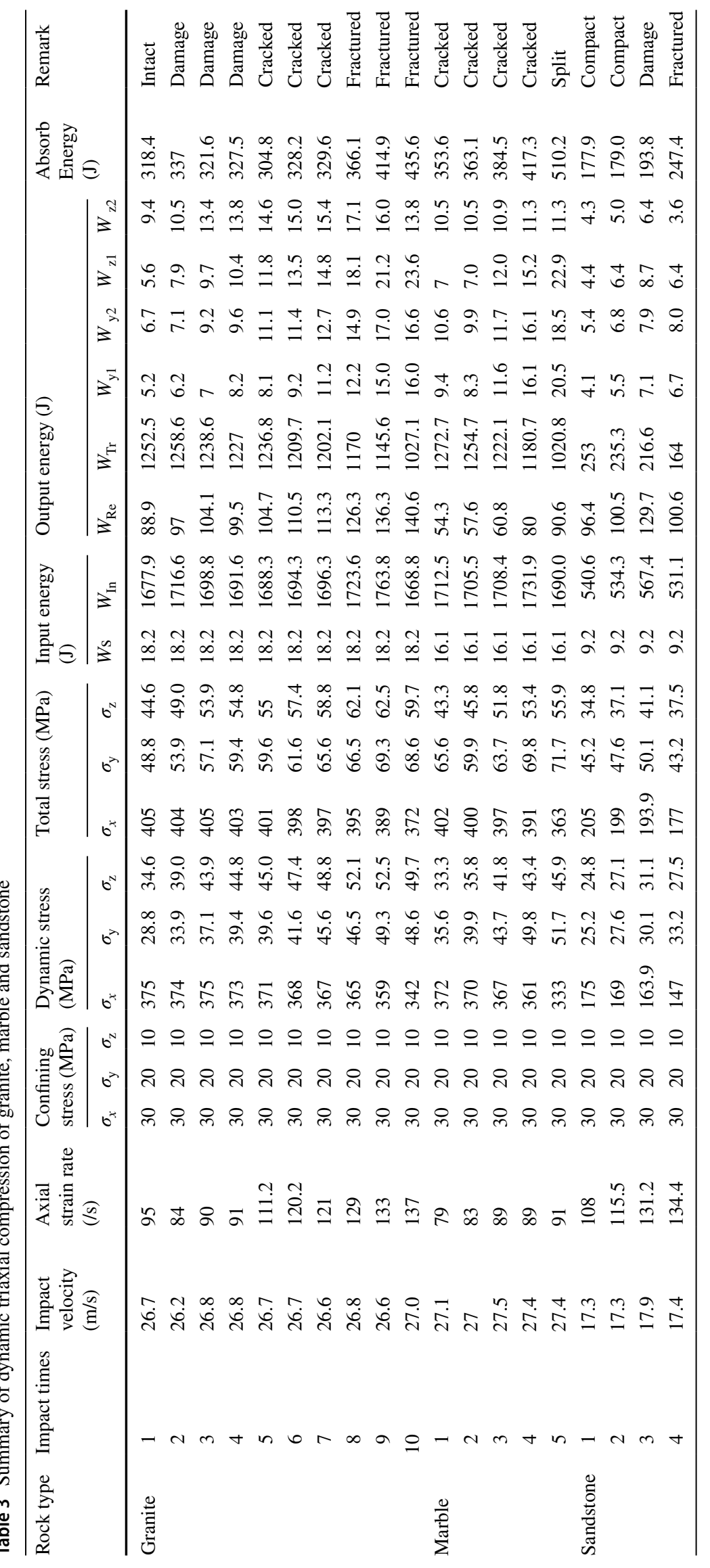




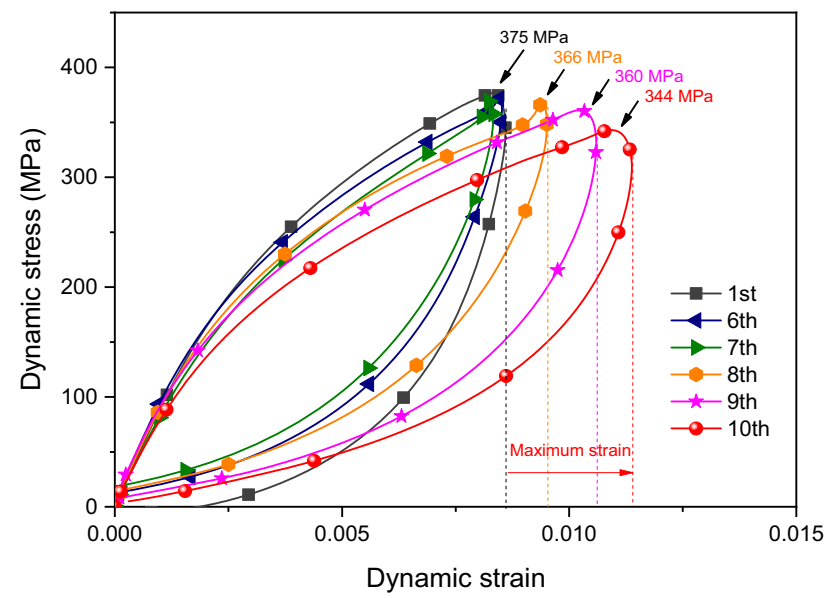

(a)

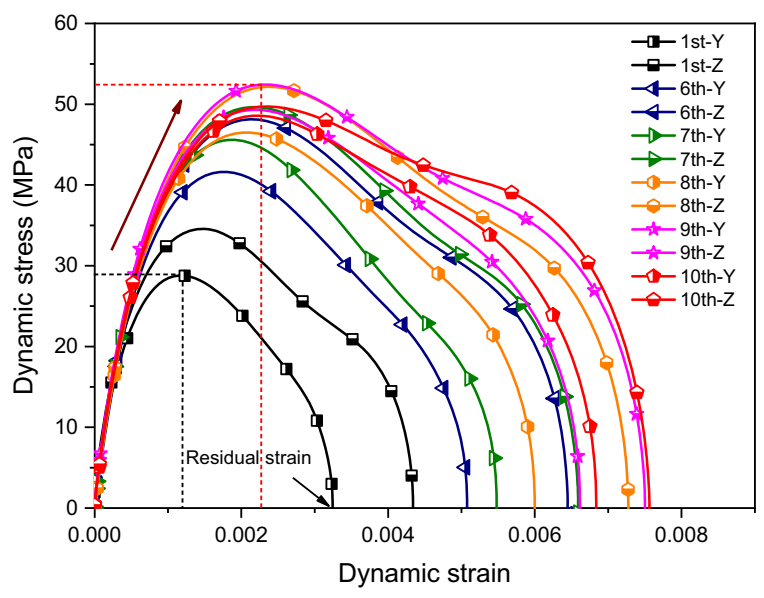

(b)

Fig. 9 Dynamic stress-strain curves of granite under a triaxial prestress state of $(30,20,10) \mathrm{MPa}$ and a repetitive impact velocity of $27 \mathrm{~m} / \mathrm{s}$ : a dynamic stress-strain history in $\mathrm{X}$ direction; b dynamic stress-strain history in $\mathrm{Y}$ and $\mathrm{Z}$ directions

in Fig. 12a, the time of maximum strain increases from 188 to $211 \mu \mathrm{s}$. Besides, the peak strain rates $\dot{\varepsilon}_{p}$ increases with impact times due to cumulative damage and stiffness degradation in rock. Similar characteristics can be observed in the marble (Fig. 12b) and sandstone (Fig. 12c). This finding suggests that under the same seismic load, the strain rate field of rock mass is localized the around the rock faults and that a pre-damaged rock is easier to pulverize. This also implies that pulverized rocks observed on the field may result from successive loadings (Doan and d'Hour 2012; Doan and Gary 2009).

\subsection{Size Evolution}

Figure 13 shows the deformation evolution of rocks after each static-dynamic load. During the impact, the specimen was compressed in the $\mathrm{X}$ direction and thus became

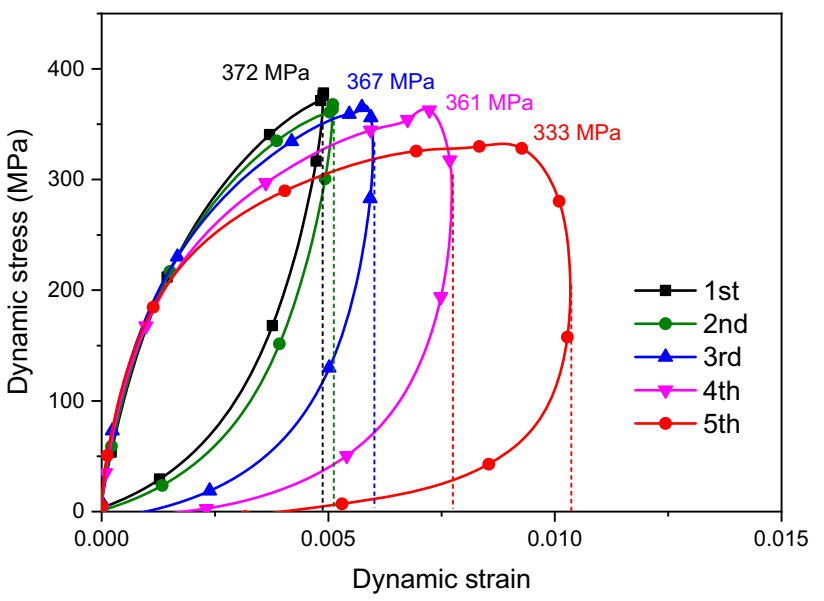

(a)

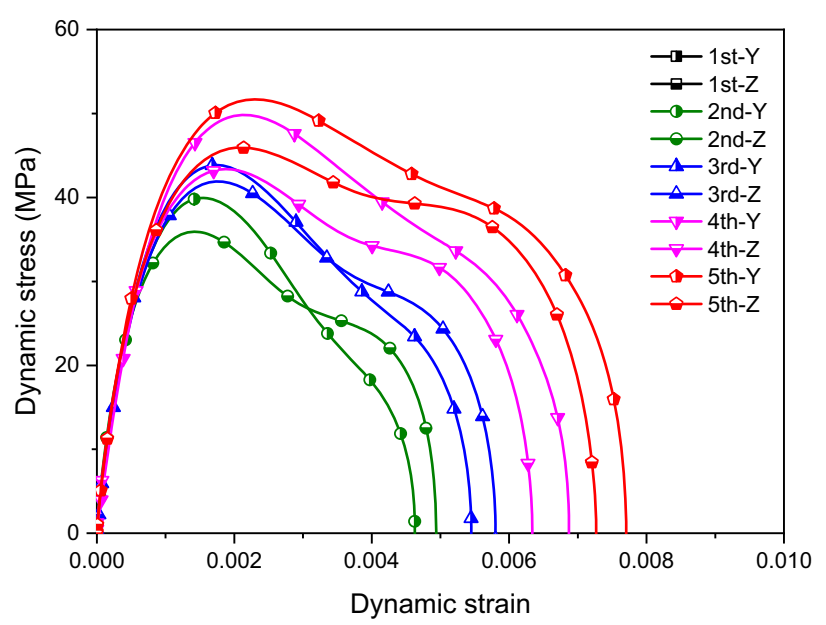

(b)

Fig. 10 Dynamic stress-strain curves of marble under a triaxial prestress state of $(30,20,10) \mathrm{MPa}$ and a repetitive impact velocity of $27 \mathrm{~m} / \mathrm{s}$ : a dynamic stress-strain history in $\mathrm{X}$ direction; b dynamic stress-strain history in $\mathrm{Y}$ and $\mathrm{Z}$ directions

shorten. However, along the $\mathrm{Y}$ and $\mathrm{Z}$ directions, the specimen expanded linearly due to the Poisson's effect. The expansion of rock in the $\mathrm{Z}$ direction is larger than that of $\mathrm{Y}$ direction because of the difference of the initial stresses $\sigma_{\mathrm{y} \text {-static }}=20 \mathrm{MPa}$ and $\sigma_{\mathrm{z} \text {-static }}=10 \mathrm{MPa}$ applied on specimen, which is in consistent with that observed from the dynamic stress-strain curves. Besides, the volume of the specimen seems to increase linearly with the impact times due to the development of micro-cracks.

\subsection{Acoustic Characteristics}

\subsubsection{Ultrasonic Wave Velocity and Attenuation}

Ultrasonic testing as a non-destructive tool is one of the most widely used method for rock characterization and 


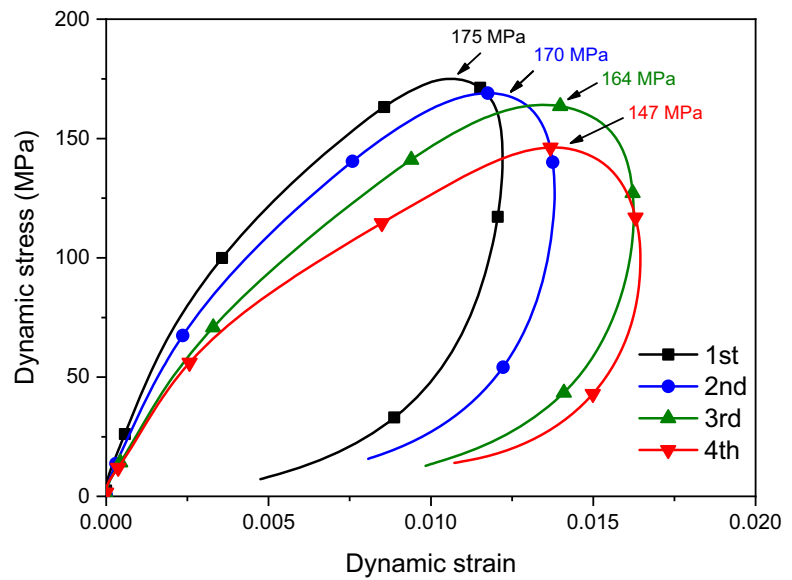

(a)

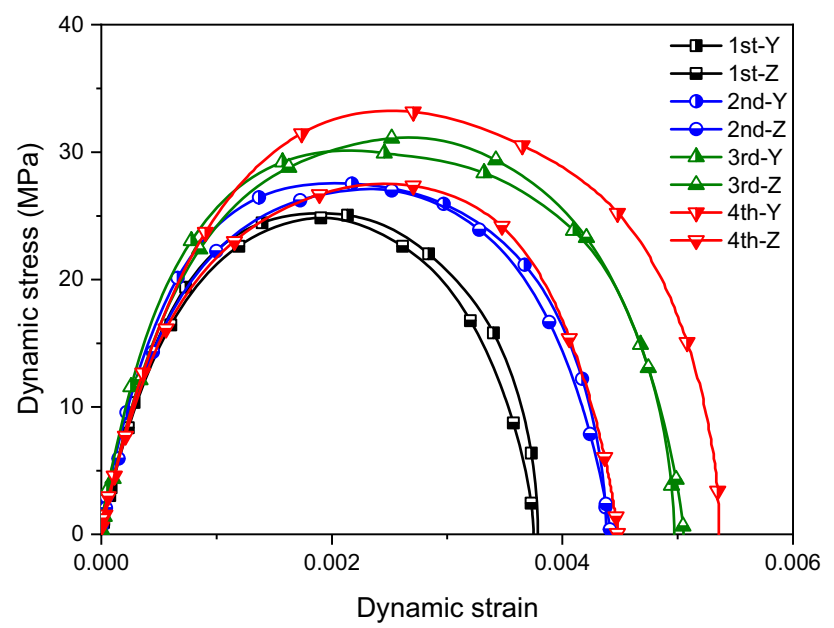

(b)

Fig. 11 Dynamic stress-strain curves of sandstone under a triaxial pre-stress state of $(30,20,10) \mathrm{MPa}$ and a repetitive impact velocity of $17 \mathrm{~m} / \mathrm{s}$ : a Dynamic stress-strain history in $X$ direction; $\mathbf{b}$ dynamic stress-strain history in $\mathrm{Y}$ and $\mathrm{Z}$ directions

examination of damage (Lama and Vutukuri 1978; Rummel and Vanheerden 1978). The ultrasonic wave velocity, amplitude attenuation and their amplitude-frequency spectra are affected by the material's physical and mechanical properties that are strongly related to the microstructural characteristics (Aydin 2013; Chaki et al. 2008). To qualify the progressive damage of rock under dynamic repetitive triaxial compression, the ultrasonic velocities of $\mathrm{P}$ and $\mathrm{S}$ waves, ultrasonic pulse shape, and amplitude-frequency spectra of the received ultrasonic waves were examined in the $\mathrm{X}, \mathrm{Y}$ and $\mathrm{Z}$ directions, respectively.

During the impact, the rock is fatigued with induced micro-cracks, and the damage value $D$ of rock is qualified by the attenuation coefficient of wave velocity:
$D_{i, j}=\frac{V_{0, j}-V_{i, j}}{V_{0, j}}, i=0,1,2 \cdots N-1, N ; j=x, y, z$

where $D_{i, j}$ is the damage value, $i$ and $j$ are the specified impact time and measurement direction, respectively; $N$ is the total impact time.

The wave velocities were measured before and after each impact under the triaxial confinement, and the results are plotted in Fig. 14. As expected, there is a negative correlation between the wave velocities and impact times, as shown in Fig. 14a, both of $\mathrm{P}$ and $\mathrm{S}$ wave velocities decreased with increasing impact times. The generation and propagation of micro-cracks degrade the rock specimen and thus lead to a macroscopic decrease of wave velocity. Besides, the reduction of $\mathrm{P}$ wave velocity of granite in the $\mathrm{Z}$ direction is much larger than that of $\mathrm{X}$ and $\mathrm{Y}$ directions. The reason is that micro-cracks propagated along the impact $X$ direction (maximum principal stress) and perpendicular to the $\mathrm{Z}$ direction (minimum principal stress), and the specimen had the largest deformation in the $\mathrm{Z}$ direction. It is worthy to note that, wave velocities decrease considerably after the 7 th impact, indicating that micro-cracks propagated and coalesced pervasively across the fatigued specimen. The damage values of granite characterized by wave velocities are presented in Fig. 14b, where one can see that the damage values exhibit a positive relation with increasing impact times. The damages in the $\mathrm{Z}$ direction are higher than that of $\mathrm{Y}$ and $\mathrm{Z}$ directions, and they all increase sharply after 7 th impact. These results agree with dynamic stress-strain evolutions in the Fig. 9a at Sect. 3.2. For marble and sandstone, the $\mathrm{P}$ and $\mathrm{S}$ wave velocities decrease while the damage values increase with impact times. However, it seems to be difficult to identify the turning point that the rocks fail completely, suggesting a different fatigue and damage mechanism with that of granite.

\subsubsection{Waveform Analysis of Ultrasonic Waves}

For crystallized materials like rock, the distribution of induced microstructure has a significant influence on the propagation and scattering of ultrasonic waves. Rocks with different microstructural are considered as unique frequencyselecting filters (Aydin 2013; Li and Ma 2009; Li et al. 2010; Santos et al. 2010). Therefore, by transforming the travelled signals from time domain $f(t)$ to the frequency domain $f(\omega)$, the microstructure evolution of rock is observed.

The amplitude spectra of received ultrasonic waves stemmed from rock specimen at different impact times were calculated by the application of fast Fourier transformation, which decomposes a function of time (a signal) into its constituent frequencies. The amplitude frequency data of three rocks are presented in Fig. 15, and the signals here are obtained along specimen in the $\mathrm{Z}$ direction. As can be seen in Fig. 15a, c, e, the frequency properties of the received 


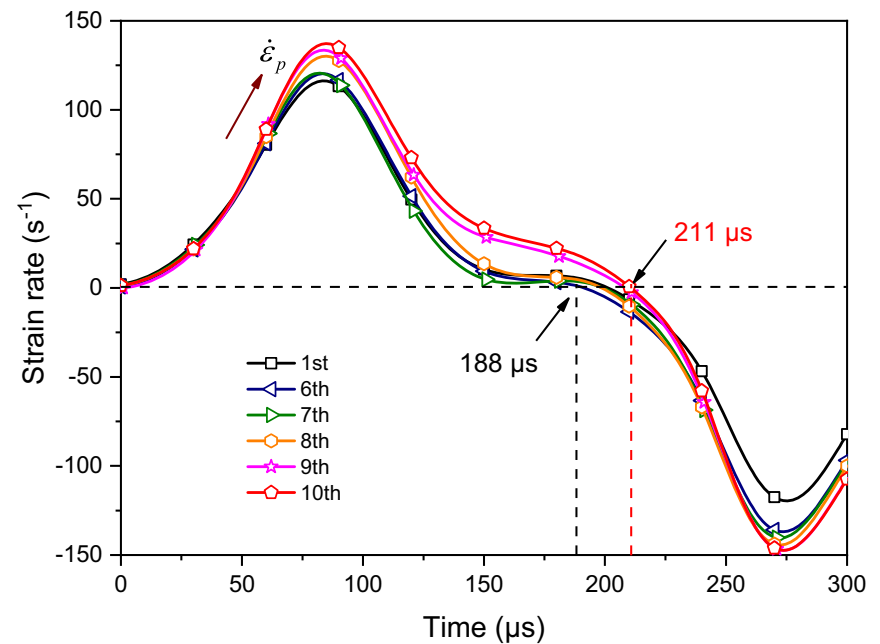

(a)

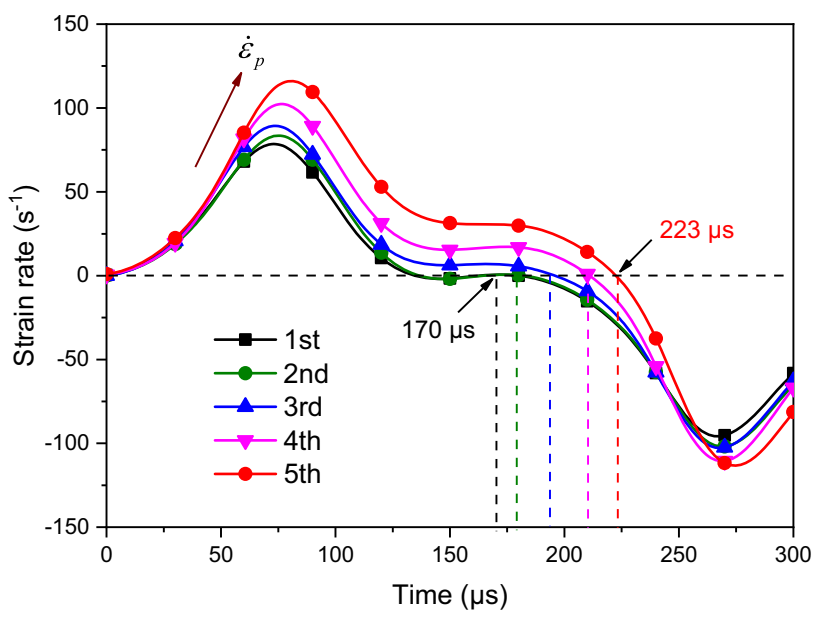

(b)

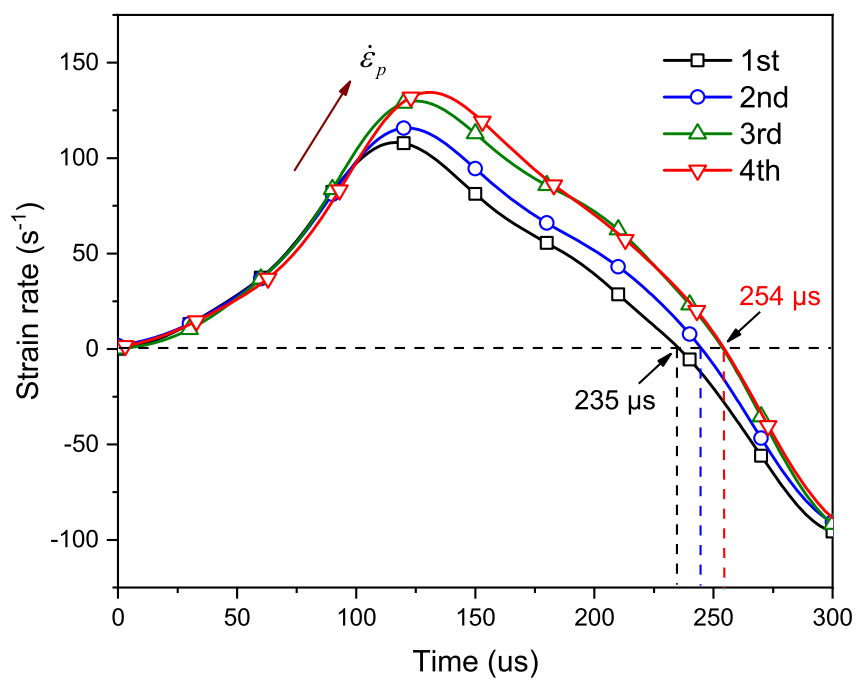

(c)

Fig. 12 Strain rate evolution during the repetitive impacts under a triaxial confinement of $(30,20,10) \mathrm{MPa}: \mathbf{a}$ granite (impact velocity $=27 \mathrm{~m} / \mathrm{s})$; b marble (impact velocity $=27 \mathrm{~m} / \mathrm{s}$ ) and $\mathbf{c}$ sandstone (impact velocity $=17 \mathrm{~m} / \mathrm{s}$ )

ultrasonic waves changed with increasing impact times, due to the accumulative microstructure and progressive damage under repeated impacts. For all rock types, the highfrequency parts of the received ultrasonic waves decrease with increasing impact time, and the low frequency parts become dominant as the microstructure and defects generated progressively during each impact. Besides, when frequency spectrums are zoomed in between 0 and $200 \mathrm{kHz}$ (Fig. 15b, d, f), it is interesting to find out that, multiple distinct frequency spectrum ranges are detected and amplitudes attenuated with increasing impact times. The damaged rock filters the high frequencies of ultrasonic waves and saves the low ones. Additionally, the scattering in the frequency and amplitude attenuation shows different patterns with rock types, this generally results from different induced damage mechanism in grain scale.

\subsection{X-Ray Microtomography}

\subsubsection{Crack Network Evolution}

Figure 16 shows the $\mu \mathrm{CT}$ crossion images of granite under dynamic repetitive triaxial compression. The full crossion sections (a-o) are obtained from the same slice number in three directions that presented in Fig. 16p. Note here that the impact direction is along the maxinum principal stress $\sigma_{1}$. As shown in Fig. 16b, g, i, the initiated micro-cracks, most exhibiting in shear, were visible after the 4 th impacts. 


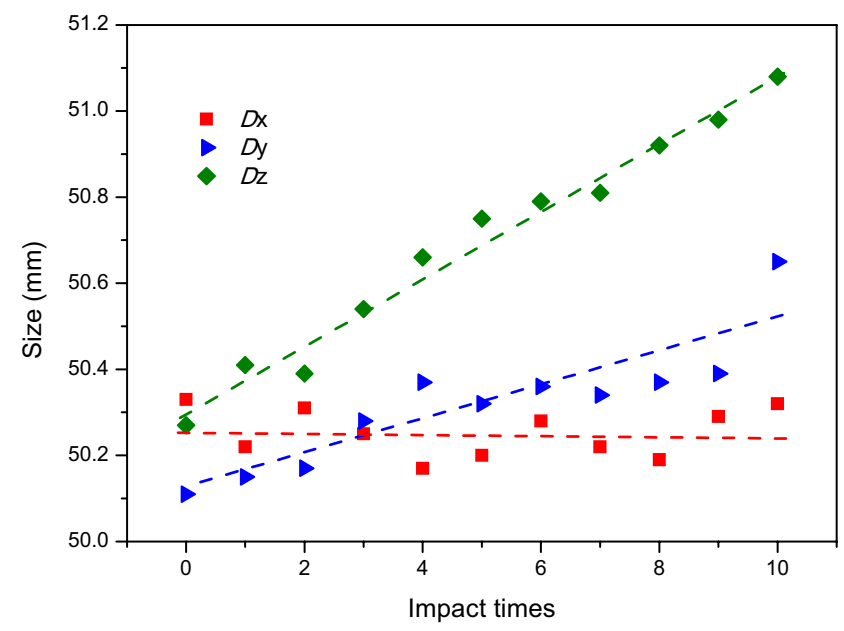

(a)

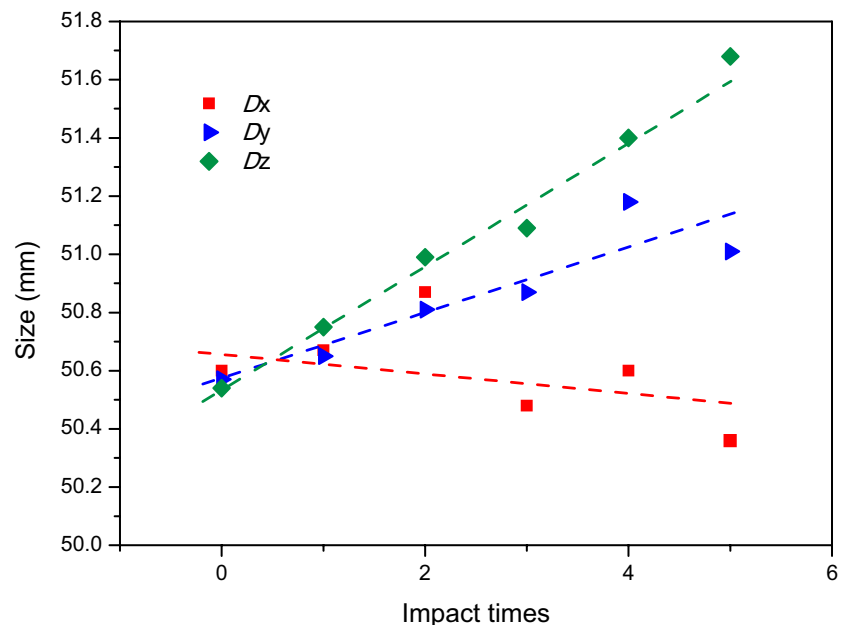

(b)

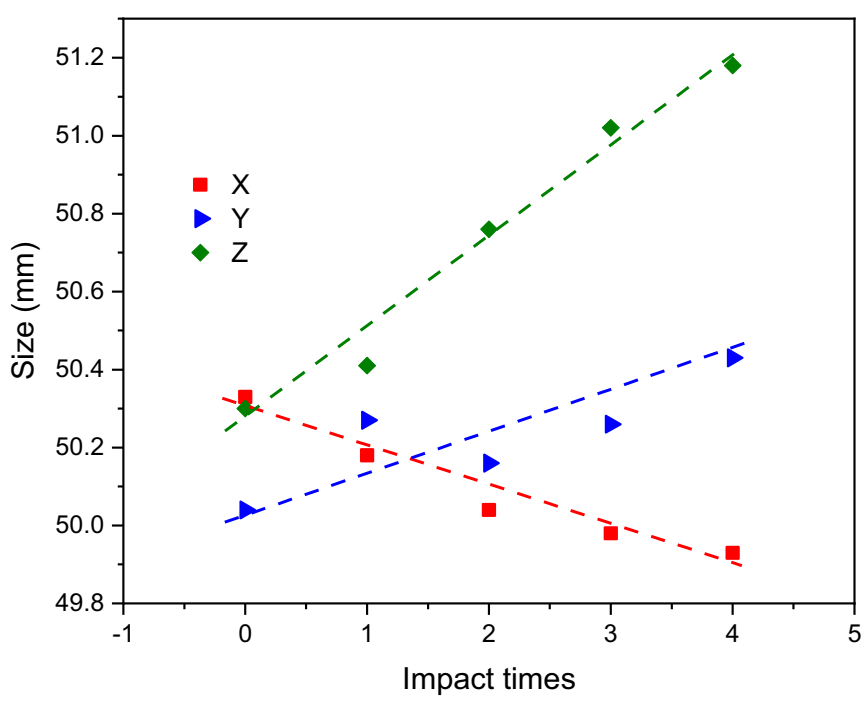

(c)

Fig. 13 Size evolution of rocks during repetitive impacts under a triaxial confinement of $(30,20,10) \mathrm{MPa}$ : a granite (impact velocity $=27 \mathrm{~m} / \mathrm{s}$ ); b marble (impact velocity $=27 \mathrm{~m} / \mathrm{s}$ ) and c sandstone (impact velocity $=17 \mathrm{~m} / \mathrm{s}$ )

The micro-cracks then propagated progressively from the corner to middle part of the specimen with increasing impact times from 4 to 10. Also, it can be seen from Fig. 16d, i and $\mathrm{n}$ that the shear bands exhibit different angles, e.g. $37^{\circ}, 20^{\circ}$ and $30^{\circ}$ in $X Y, Y X$ and $X Z$ planes, respectively. Finally, after the 10th impact, the shear bands intersected each other and coalescenced across the whole volume.

On a smaller scale, it can be observed in Fig. 16q, r, t that micro-cracks propagated across the mineral grains, such as biotite grains, which is defined as transgranular cracking. Besides, crack surfaces show a stepwise pattern with a certain of roughness. The intergranular cracking (Fig. 16q) also occurred along the biotite boundary during the impact. Because the grey values of mineral grains like quartz and feldspar are very close, it is difficult to identify whether the transgranular or intergranular is prominent from these $\mu \mathrm{CT}$ images. To address this, optical microphotographs by thin section will be further disscussed in the below section.

In addition to intergranular and transgranular cracking, variable crack branching are obeserved and presented in Fig. 16s, u. Crack branching is commonly caused by the crack interaction in the form of en echelon linking or en passant linking (Blenkinsop 2007; Kranz 1979). As shown in Fig. 16s, the branching caused by en echelon interactions occured between two straight, sub-parallel micro-cracks, which are generally linked by a third straight micro-crack. However, Fig. 16u presents crack branching induced by en passant linking, which involves deviation of micro-cracks due to the interaction of micro-crack tip stress fields between each other. Specifically, crack arrest also occurred when the 


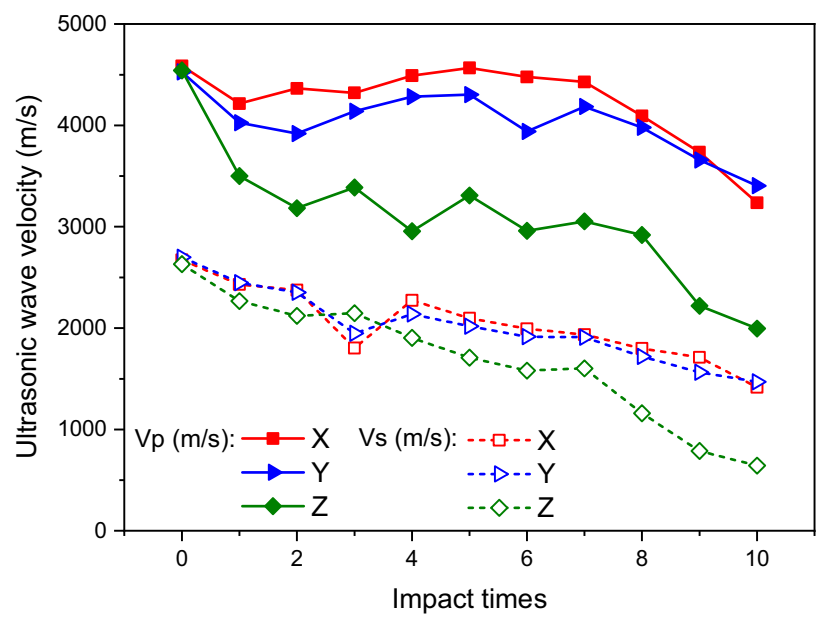

(a)

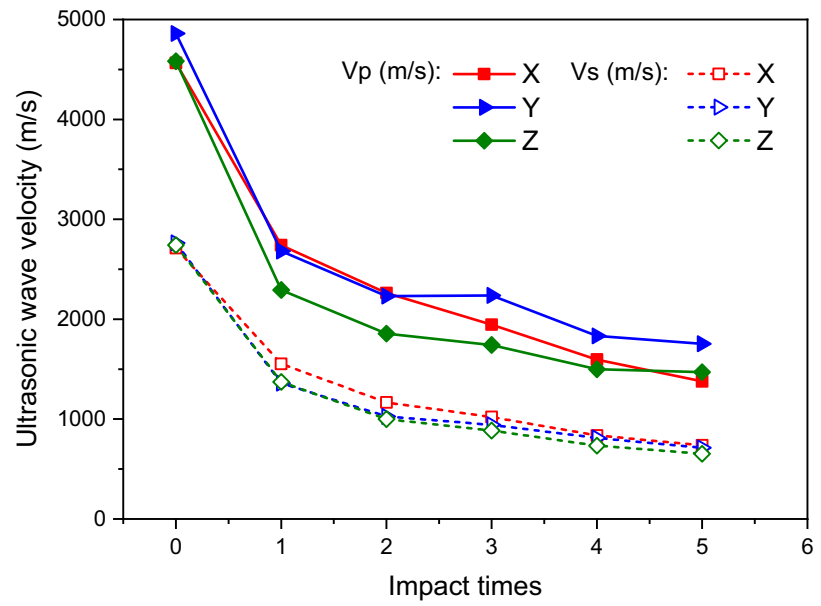

(c)

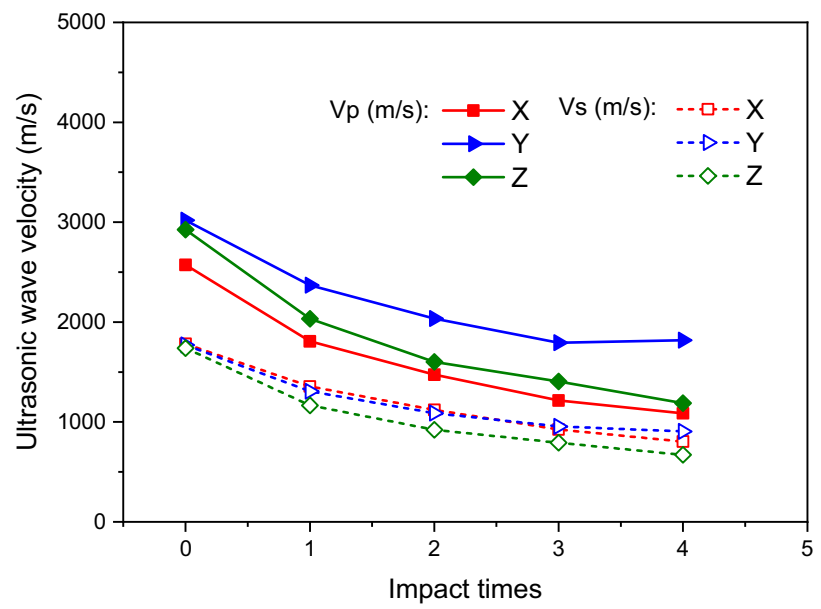

(e)

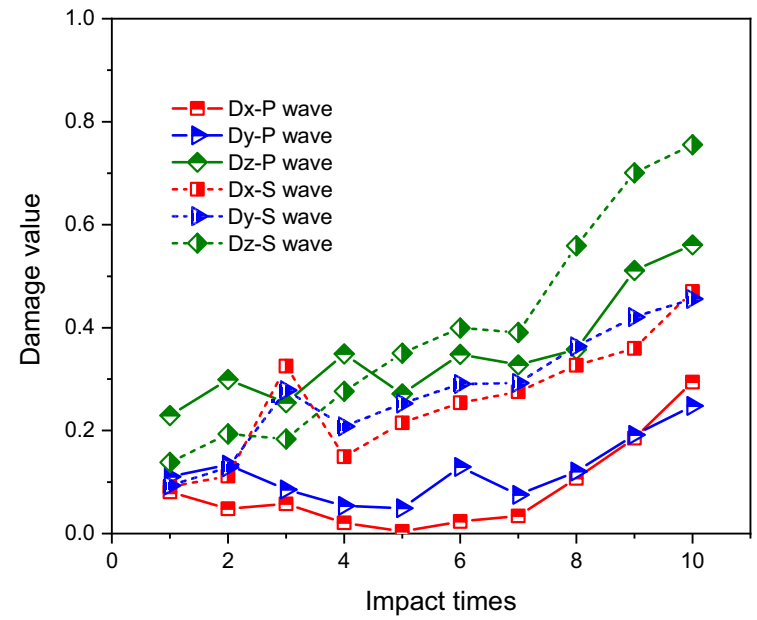

(b)

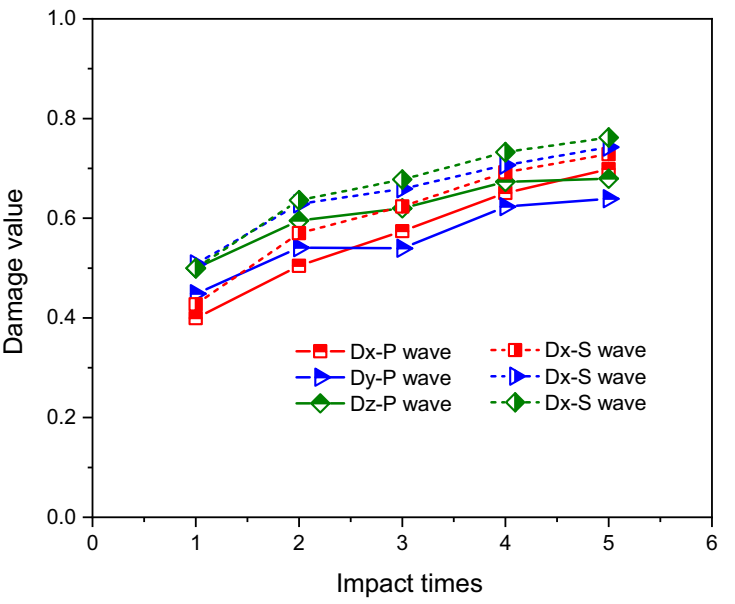

(d)

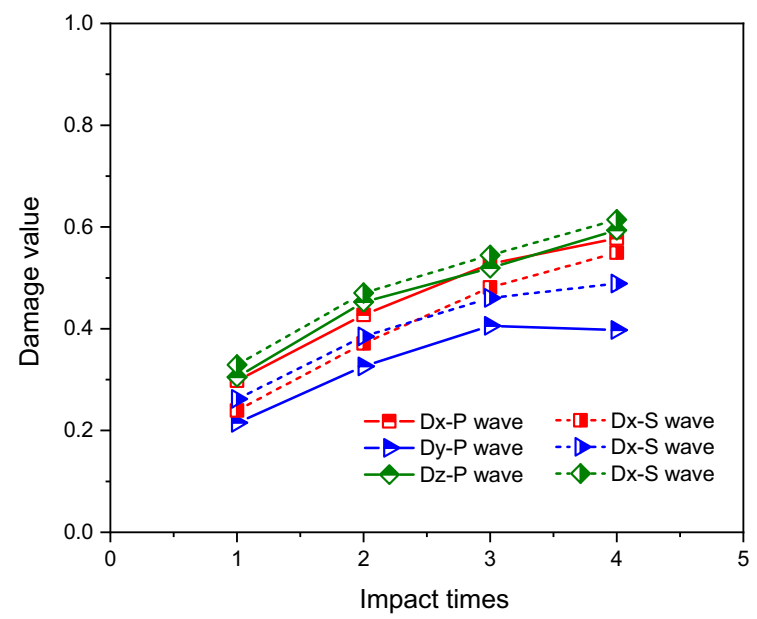

(f)

Fig. 14 Ultrasonic wave velocity and damage evolution of rock with increasing impact times: $\mathbf{a}, \mathbf{b}$ granite; $\mathbf{c}, \mathbf{d}$ marble; $\mathbf{e}, \mathbf{f}$ sandstone 

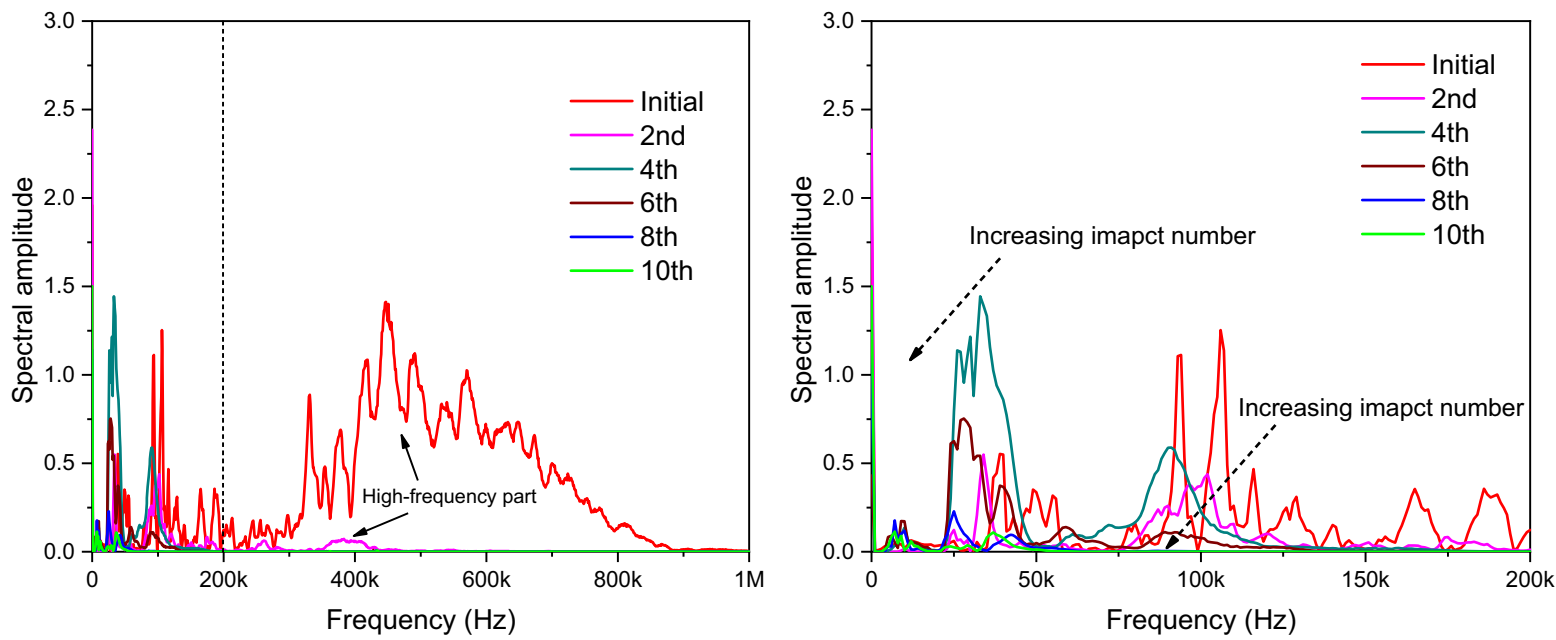

(a)

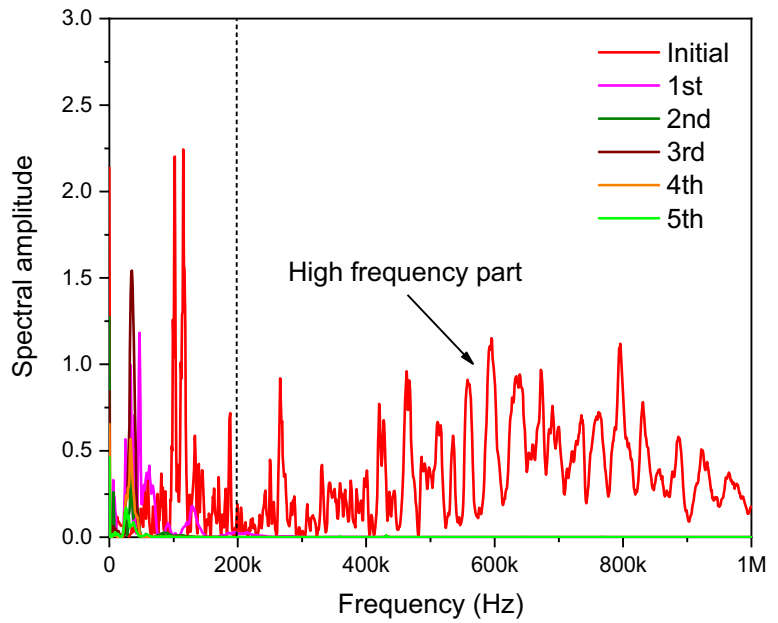

(b)

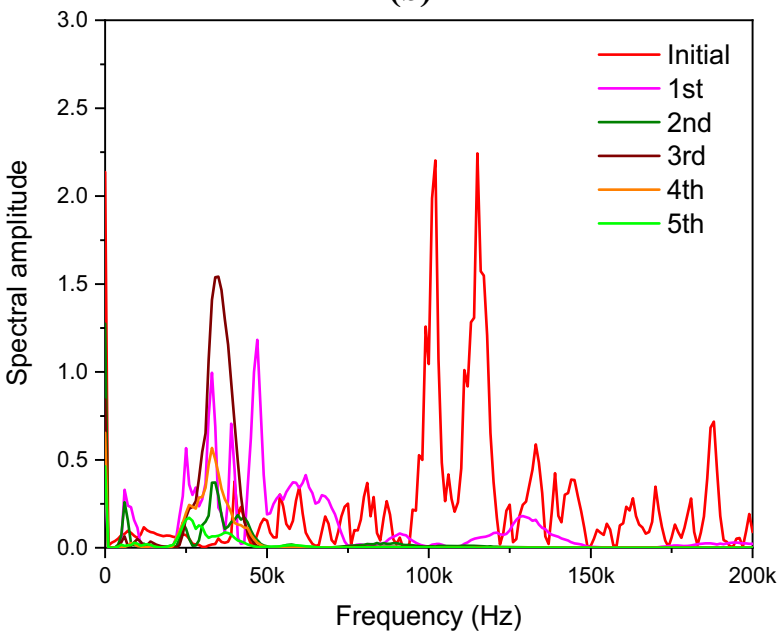

(c)

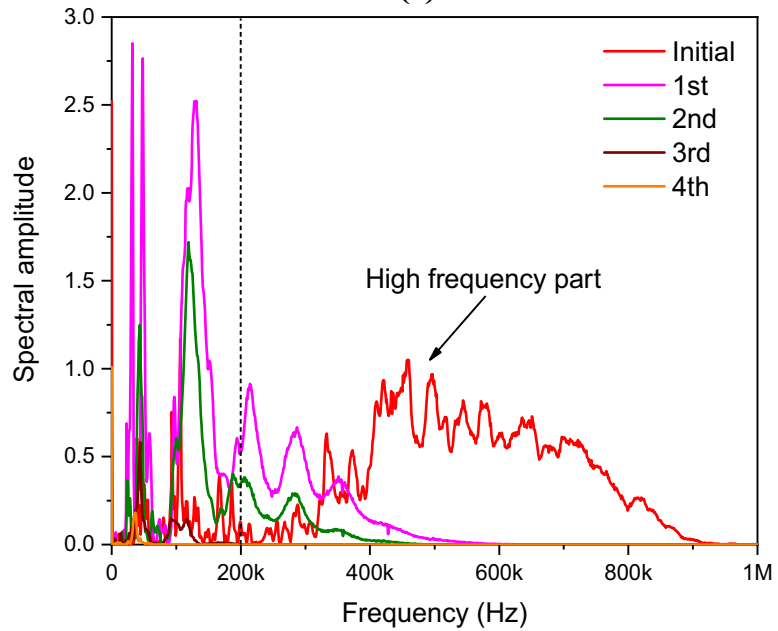

(e)

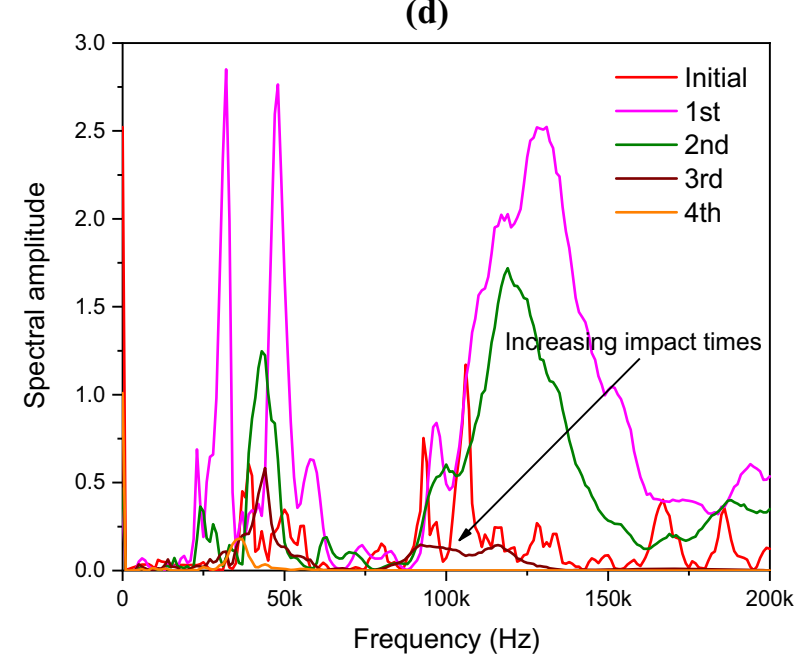

(f)

Fig. 15 Amplitude spectrum of ultrasonic waves in rocks with increasing impact times: a, $\mathbf{b}$ granite; $\mathbf{c}, \mathbf{d}$ marble; $\mathbf{e}, \mathbf{f}$ sandstone 
Initial state
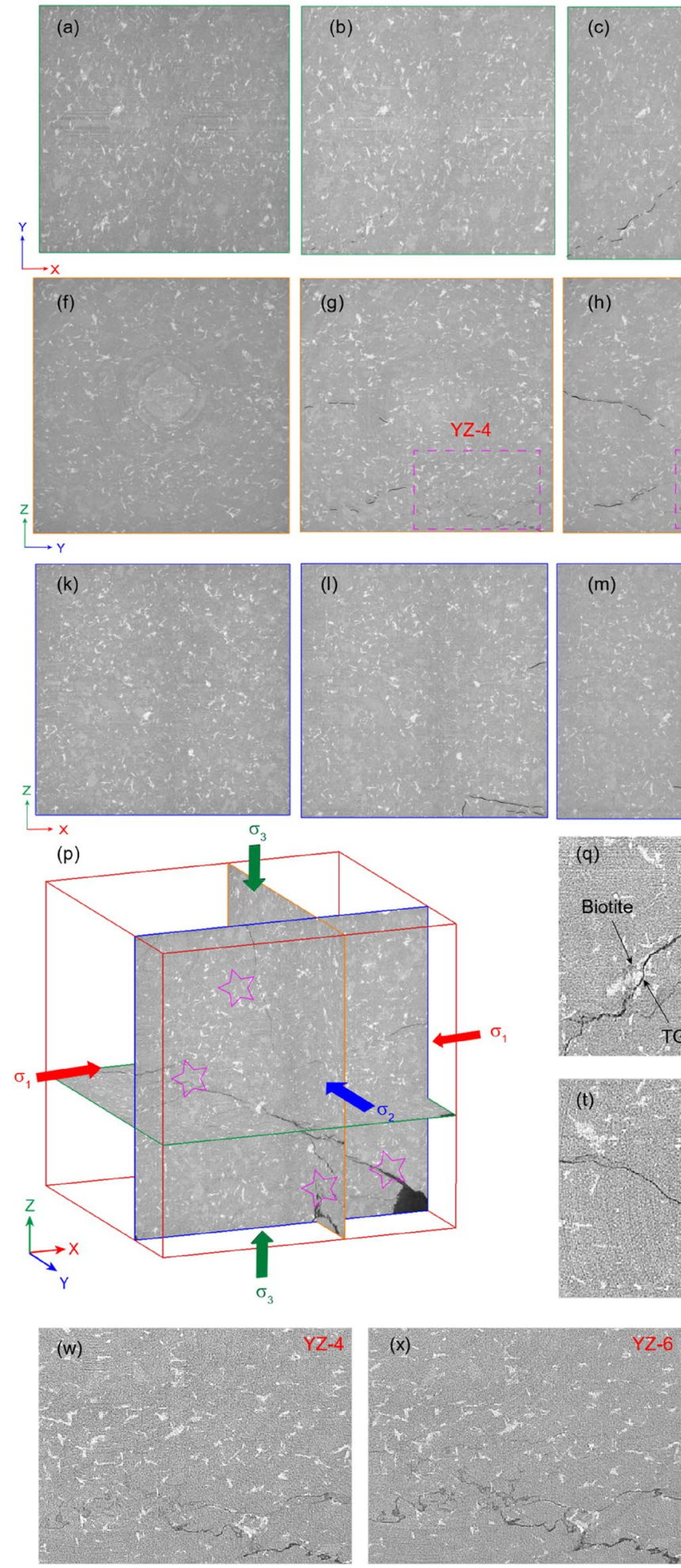

Fig. $16 \mu \mathrm{CT}$ crossion images (pixel size: $18.3 \mu \mathrm{m}$ ) of the progressive damage of granite under dynamic triaxial compression, showing micro-cracking in three orthogonal directions: a-e Slices from XY plane, f-j Slices from YZ plane, and k-o Slices from XY plane; The 8th impact

10th impact
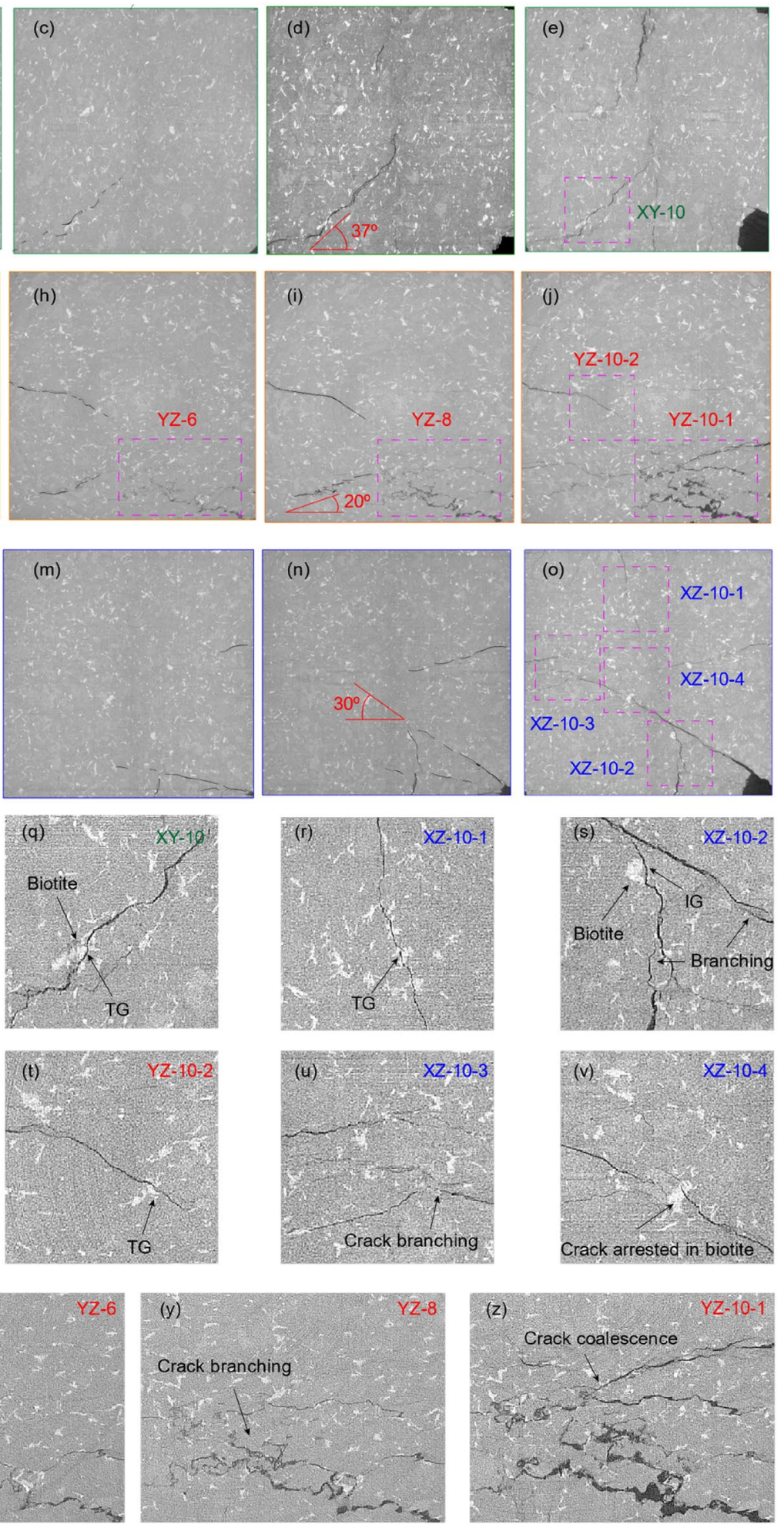

positions of the silce and the local observation areas in $\mathbf{p}$. The closer looks of various failure patterns at the specified windows in $\mathbf{q}-\mathbf{z}(I G$ intergranular cracking, $T G$ transgranular cracking) 
crack tip was stopped by biotite grains with higher elastic modulus.

Figure $16 \mathrm{w}-\mathrm{z}$ present the enlarged views of damage zone of granite in the YZ plane from 4 to 10 impact times. Micro-cracks that initiated during 4th impact distributed discontinuously along a shear band within the specimen volume. After the 8th impact, with the development of damage, micro-cracks branched off along the grain boundaries and produced obvious shear bands. With increaing impact times to 10 , the crack coalescenced as well as the local grain breakage appeared, leading to the pervasive damage of granite specimen.

The X-ray microtomography acquisition on rock after each static-dynamic impact shows the propgressive development of fracture network. Table 4 shows the fracture network evolution of granite under a triaxial pre-stress of (30, $20,10) \mathrm{MPa}$ and the repetitive impact velocity of $27 \mathrm{~m} / \mathrm{s}$, corresponding to the strain rate of 100-150/s. Note here that the impact direction ( $\mathrm{X}$ direction) is along the maxinum principal stress $\sigma_{1}$. The 3D-reconstruction of fracture network presents that the granite damaged slightly at the first three static-dynamic coulpling loads, accompanied with a shear band generated and propagated from the corner, which results in similar dynamic stress-strain behaviors. In the 4th impact, the shear band propagated further into the specimen. Besides, several sets of micro-cracks initiated in the middle part. With increasing impact times to 7 , micro-cracks propagated along the impact direction (maximun principal stress direciton $\sigma_{1}$ ) and intercted with each other. Notablely, starting from the 8th impact, a large number of micro-cracks developed fully throughout the granite, leading to a high degree of connectivity in the macroscopic fracture network. Although experienced 10th impacts, the whole specimen still kept high cohesion.

Crytallized rocks like granite are highly heterogeneous with diffenrent minerals and grains, and also contain randomly distributed micro-cracks. When a granite is stressed, the heterogeneity leads to local concentrations of tensile and shear stresses distributed at the micro and meso scale(Denoual et al. 1997). Micro-cracks initiate locally in the material once the local stress reaches the specified strength, and they usually bend in the direction of lower yield stress or tend to arrest if suffering a grain of higher strength like quartz or lower local stress(Renard et al. 2009). During the propagation, the crack tips can be also sudjected to the random mode II loading and then change the direction, which makes the fracture surfaces with a certain roughness (Bouchaud et al. 2002). The heterogeneous deformation such as grain dislocation, crushing and rotation results in the initiation, propagation and coalesce of internal flaws, including interguanlar and transgranular cracks (Blair and Cook 1998). For the granite under static-dynamic coupling loads, there is an increase in micro-crack numbers with increasing impact times. Except for the main shear band, some micro-cracks with random directions also generate during the repetitive loads. Due to the crack intersection and coalescence, some

Table 4 3D visualization of fracture network evolution of granite under the triaxial pre-stress of $(30,20,10) \mathrm{MPa}$ and a repetitive impact velocity of $27 \mathrm{~m} / \mathrm{s}$

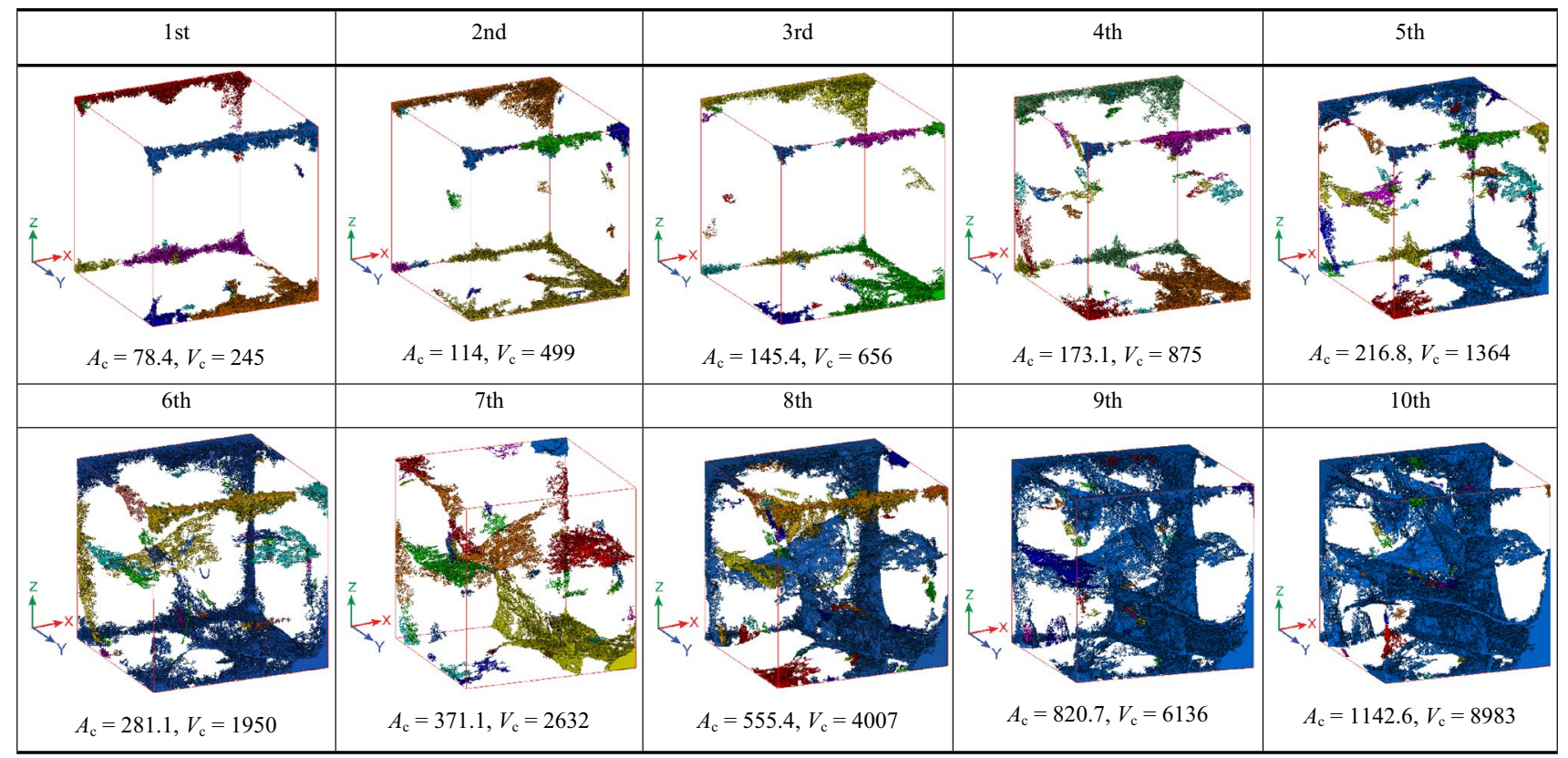

$A_{\mathrm{c}}$ is the total crack surface area, $\mathrm{mm}^{2}, V_{\mathrm{c}}$ is the total crack volume, $\mathrm{mm}^{3}$. The colour indicates different groups of micro-cracks in the specimen volume 
Table 53 D visualization of fracture network evolution of marble under the triaxial pre-stress of $(30,20,10)$ MPa and a repetitive impact velocity of $27 \mathrm{~m} / \mathrm{s}$

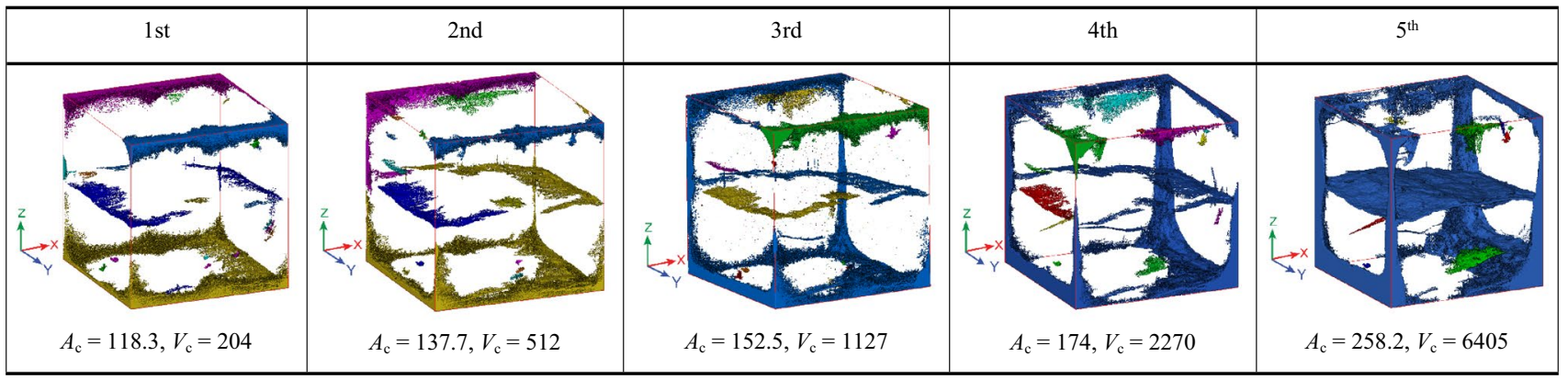

$A_{\mathrm{c}}$ is the total crack surface area, $\mathrm{mm}^{2}, V_{\mathrm{c}}$ is the total crack volume, $\mathrm{mm}^{3}$. The colour indicates different groups of micro-cracks in the specimen volume

obvious cracks branched and propagated with an angle to the main shear band are observed.

Compared to the heterogeneous granite, marble is also brittle but with homogeneous grains. Under the same loading condition as that of granite, one can see in the Table 5 that two cracks initiated on the middle part of the incident and transmission surfaces of marble, respectively. Then, they propagated towards the center part with increasing impact times. The scans taken after the 5th impacts reveal that these two cracks coalesced to form a macro-fracture whose direction is nearly parallel to the impact loads and the marble was finally split in two parts. The damage mechanism of marble is somehow different with granite, because marble has homogeneous, pure and crystalline grains. After initiation, micro-cracks underwent a straight propagation stage without surffering the high local stress concentration. Few branching crack as well as localized brittle fracture were observed.

Table 6 presents the fracture network of sandstone under the triaxial pre-stress of $(30,20,10) \mathrm{MPa}$ and the repetitive impact velocity of $17 \mathrm{~m} / \mathrm{s}$. Apparently, the damage mechanism of sedimentary sandstone is different with that of granite and marble. Sandstone containing quartz, feldspar and weak rgillaceous cement allows a larger deformation once compressed. During the dynamic triaxial impact, the sandstone was confined in a limited deformation space, rusulting in the compaction of micro-pores. The compaction process is accompanied by pore collapse, grain deformation, grain rearrangement and boundary degradetion. After the first two impacts, the compaction induced fractures were too small to be recognised by $\mu \mathrm{CT}$. With the increasing impact times, a deformation band generated from a compaction band. Deformation bands, in general, are developed with an angle of $30.5^{\circ}$ to the loading direction. After the 5th impact, the deformation bands coalesced to form a macro "V" shape fracture zone within the rock volume.

\subsubsection{Relationship Between Absorbed Energy and Crack Surface and Volume}

During the dynamic loads, the damage and fracture process of rocks are associated with energy consuming. The dynamic fracture energy is partitioned by the creation

Table 6 3D visualization of fracture network evolution of sandstone under the triaxial pre-stress of $(30,20,10)$ MPa and a repetitive impact velocity of $17 \mathrm{~m} / \mathrm{s}$

\begin{tabular}{|c|c|c|c|c|}
\hline Initial & 2st & 3rd \\
\hline$A_{\mathrm{c}}=19.9, V_{\mathrm{c}}=52.5$ & $A_{\mathrm{c}}=60.4, V_{\mathrm{c}}=173$ & $A_{\mathrm{c}}=123, V_{\mathrm{c}}=631$ & $A_{\mathrm{c}}=145.8, V_{\mathrm{c}}=1140$ \\
$A_{\mathrm{c}}=254.7, V_{\mathrm{c}}=2560$ \\
\hline
\end{tabular}

$A_{\mathrm{c}}$ is the total crack surface area, $\mathrm{mm}^{2}, V_{c}$ is the total crack volume, $\mathrm{mm}^{3}$. The colour indicates different groups of micro-cracks in the specimen volume 
of fracture surface area, kinetic energy and other dissipative terms during the dynamic fragmentation process (Liu et al. 2020a). For triaxial static-dynamic loads tests in this study, the input energy of specimen includes static strain energy induced by the pre-stress and dynamic strain energy induced by the impact, while the output energy can be captured on the output bars. Therefore, the energy absorbed by the specimen $W_{\mathrm{s}}$ can be calculated by the Eq. (4). Besides, the crack network, generated surface area and volume of fractures after each static-dynamic load are determined by synchrotron-based $\mu \mathrm{CT}$, as listed in Tables 4, 5 and 6 .

Figure 17 shows the evolution of absorbed energy, new crack surface and crack volume of three rock types with increasing impact times. It can be observed in the Fig. 17a that the crack surface and volume increment of granite increases nonlinearly with increasing impact times, accompanied with an increasing trend of the adsorbed energy. Specially, there is a sharp rise of adsorbed energy after the 7th impact, which results in highly damaged zone and new cracks. Similar observation of the increasement of crack parameters can be obtained for brittle marble, as shown in
Fig. 17b. These results are well consistent with the results of ultrasonic measurement presented in Fig. 14.

There is a different evolution trend of crack parameter and absorbed energy for sandstone, whose deformation is dominant by compaction and deformation bands. During the first three impacts, the porosity was gradually compacted and the grain was damaged, which consumed a relatively stable energy. While at the 4th impact, the deformation band of sandstone generated a macroscopic shear band, which results in a noticeable increasement of crack surface and volume, as demonstrated in Fig. 17c.

It is believed that normally only a portion of absorbed energy $W_{\mathrm{s}}$ is used to create new surface area and the rest of the energy is dissipated through other mechanism such as friction, noise, etc. Barber and Griffith (2017) investigated the energy consumed in creating new surface area and found that it likely constitutes of the order of 5\%, but possibly up to $40 \%$ of absorbed energy $W_{\mathrm{s}}$ for highly fragmented specimens. For triaxial compression test, confinements significantly influence the evolutions of dissipated energy, strain energy, friction, noise, and kinetic energy. It is difficult to determine the exact fraction of each energy

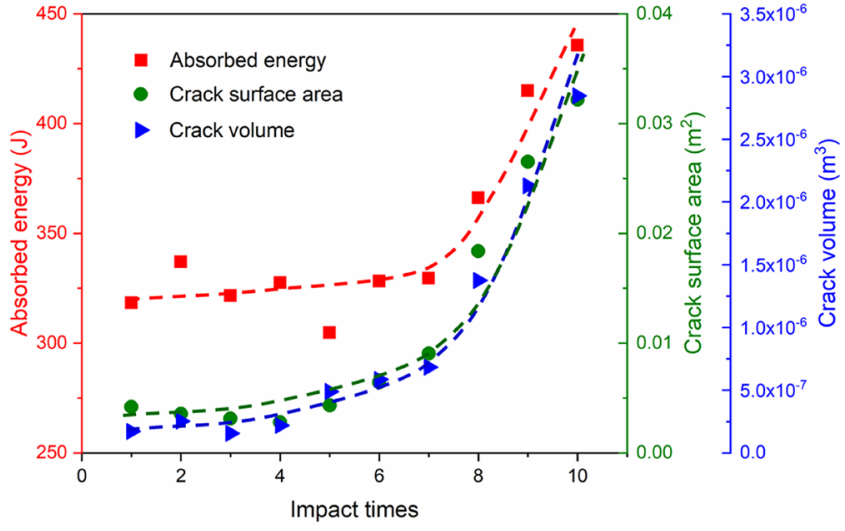

(a)

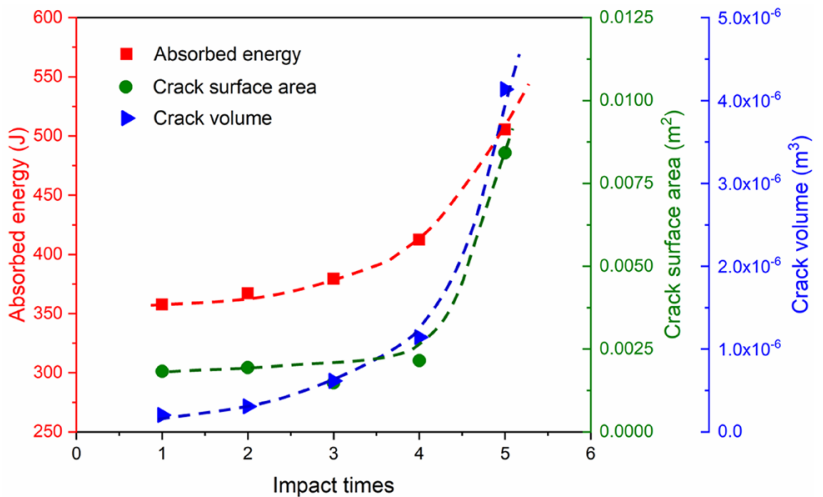

(b)

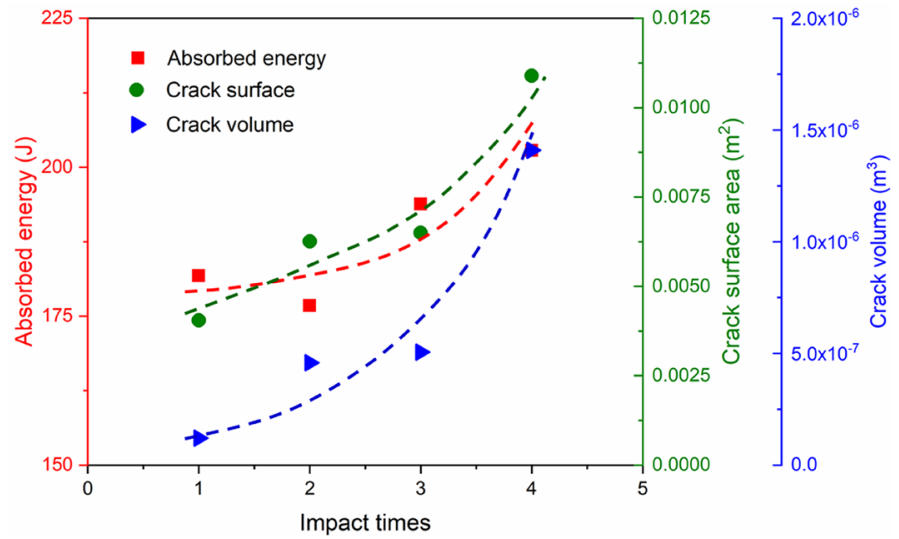

(c)

Fig. 17 The absorbed energy, crack surface and crack volume with increasing impact times: a granite; $\mathbf{b}$ marble; $\mathbf{c}$ sandstone 
terms experimentally. Based on the numerical simulation of triaxial Hopkinson bar tests (Hu et al. 2020), around $20 \%$ of the absorbed energy $W_{\mathrm{s}}$ is used to create new crack surface in sandstone under dynamic triaxial compression and the kinetic energy is less than $5 \%$ of $W_{\mathrm{s}}$. Therefore, using the data in Table 3, the absorbed energies $W_{\mathrm{s}}$ used to create new surface in sandstone under dynamic triaxial impacts are $35.6,35.8,38.8$ and $49.5 \mathrm{~J}$, with the increasing impact times from 1 to 4 , and assuming that the energy percentage for new crack surface is a constant value $(\sim 20 \%)$ at each impact. This method could be used for the determination of crack surface energy in granite and marble.

\subsection{Characterization of Fracture Mechanism}

The macroscopic fracturing of material is closely linked to the microscopic damage, and therefore it is required to conduct the post-mortem examination of fracture surface for revealing the microscopic nature of the fracture process (Ravi-Chandar and Knauss 1984; Zhang and Zhao 2014a). Post-mortem thin sections of granite after the 10th impact were taken in the $\mathrm{X}, \mathrm{Y}$ and $\mathrm{Z}$ directions, and are demonstrated in Fig. 18. Note that $\mathrm{X}$ direction is the impact direciton (i.e. maximum principal stress direction), and $\mathrm{Z}$ direction is in the mimimum principal stress direction. Firstly, images are captured at relatively low magnification to interpret the ralationship between the micro-cracks and grain

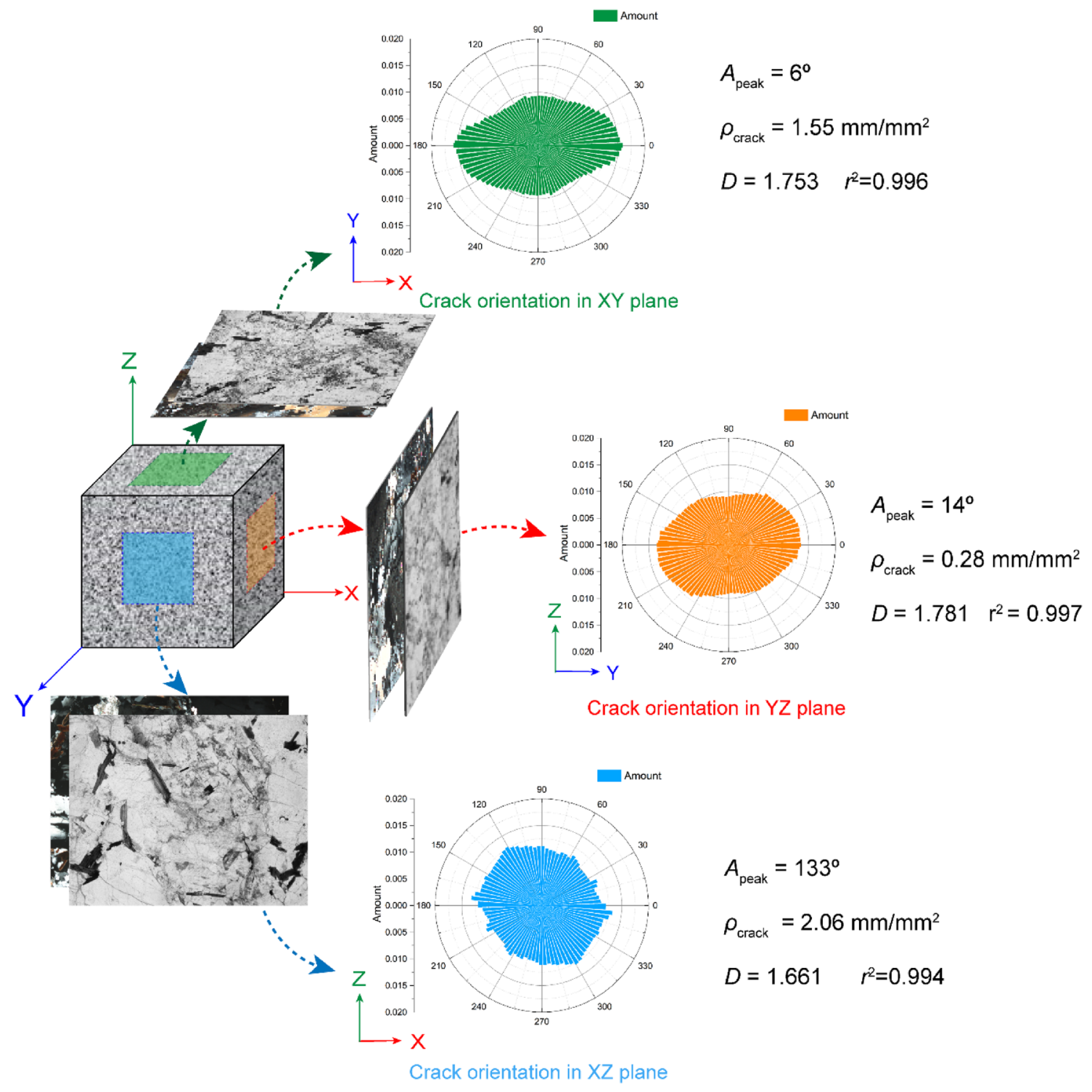

Fig. 18 Micro-crack information of granite after 10 impacts under the triaxial pre-stress state of $(30,20,10)$ MPa and a repetitive impact velocity of $27 \mathrm{~m} / \mathrm{s}$ 
parameters (e.g. grain boundaries, types and distribution). Secondly, the section images are examined inside one or two grains under high magnifications, and thus the fracture process details in subgrains are investigated. Both macro-cracks (visible with naked eyes) and micro-cracks are characterised by the microscopic images under the plane-polarised and cross-polarised lights.

\subsubsection{Intergranular and Transgranular Micro-cracks}

Figures 19, 20 and 21 show the plane polarized and crossed polarized transmitted light images in the $\mathrm{X}, \mathrm{Y}$ and $\mathrm{Z}$ directions featuring representative microstructures of granite after 10 impact times. Generally, micro-cracks are classified into three types: transgranular cracks generated across the grain; intergranular cracks propagation along grain boundaries; and transgranular-intergranular cracks, which are a combination of intergranular and transgranular cracks. In the Fig. 19a, b, it is obvious that a shear band generated acoss the specimen with an angle of $33.5^{\circ}$ to the impact $\mathrm{X}$ direction, accompanied with a large number of locally highly pulverized zones. Besides, as can be observed at the enlarged view of the grain in the Fig. 19c, d, the grains are intensely damaged and crushed with many transgranular and intergranular micro-cracks following the cleavage planes of a mineral, which resulted in the columnar debris smaller than $20 \mu \mathrm{m}$. This grain fraturing with little or no observable grain rotation is the characteristic of pulverized texture, which is a special or unque type of brecciation (Whearty et al. 2017). The volume expansion, minor shear offset and lack of grain rotation are also recognized pervasively in the brittile minerals such as quartz and plagioclase, under the triaxial confinements and multiple impacts. The pulverized quarz seems to remain in a same extincion angle, and is consistent with the observation of pulverized granite along the San Andreas and Carlock faults (Rockwell et al. 2009). Although crushed into small particles, the original grain boundaries are easily observed. The stress induced micro-cracks throughout a grain have a perfered orientation that is nearly along the impact $\mathrm{X}$ direction.

The confinements and high rate loadings contribute to the brittle grain pulverization, leading to the damage generation and pulverization in the rock faults (Aben et al. 2017; Fondriest et al. 2017; Incel et al. 2019;

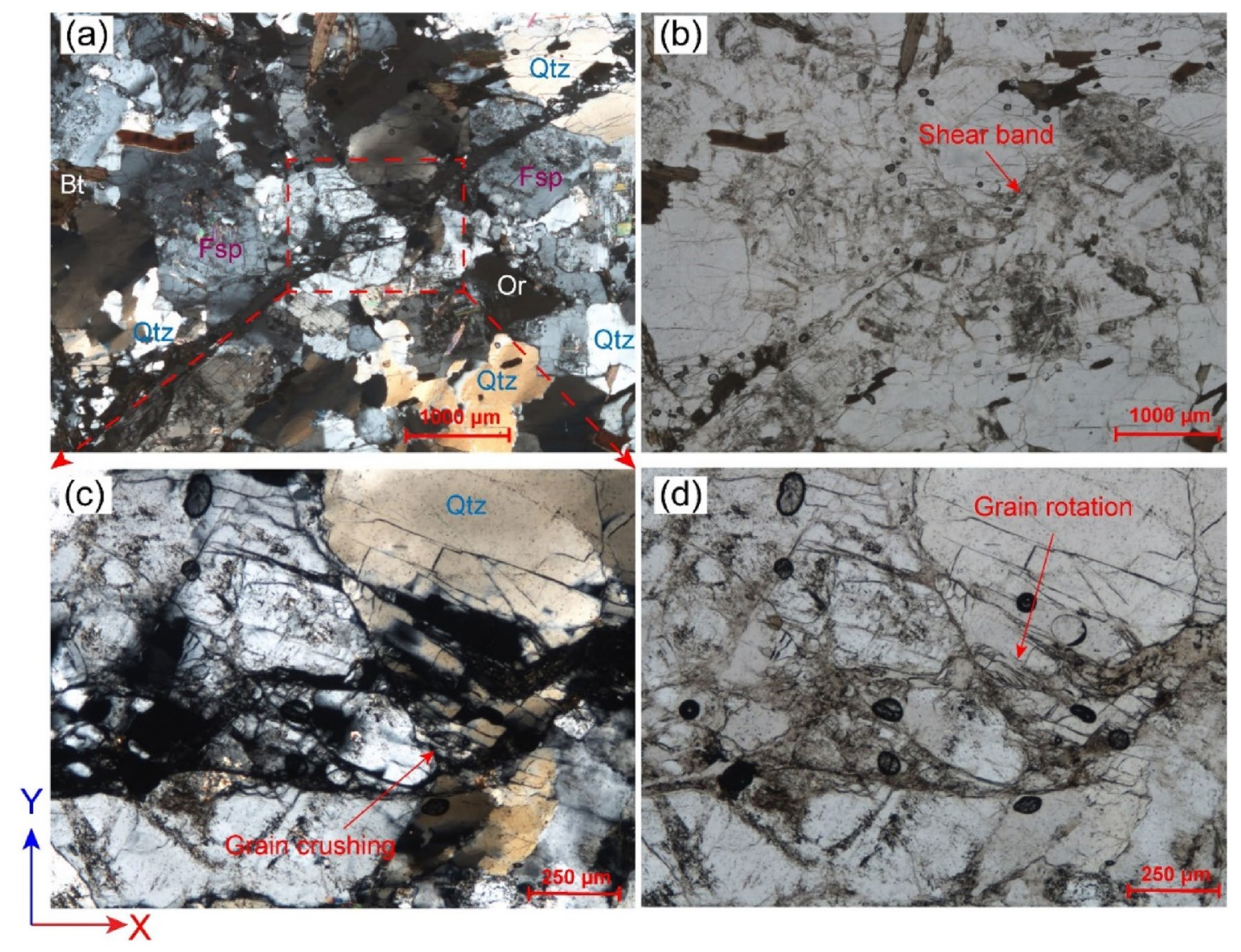

Fig. 19 Plane polarized $(\mathbf{a}, \mathbf{c})$ and crossed polarized $(\mathbf{b}, \mathbf{d})$ transmitted light images in the XY plane featuring representative microstructures of granite after 10 impacts under a triaxial pre-stress state of $(30,20,10) \mathrm{MPa}$ and a repetitive impact velocity of $27 \mathrm{~m} / \mathrm{s}$ 


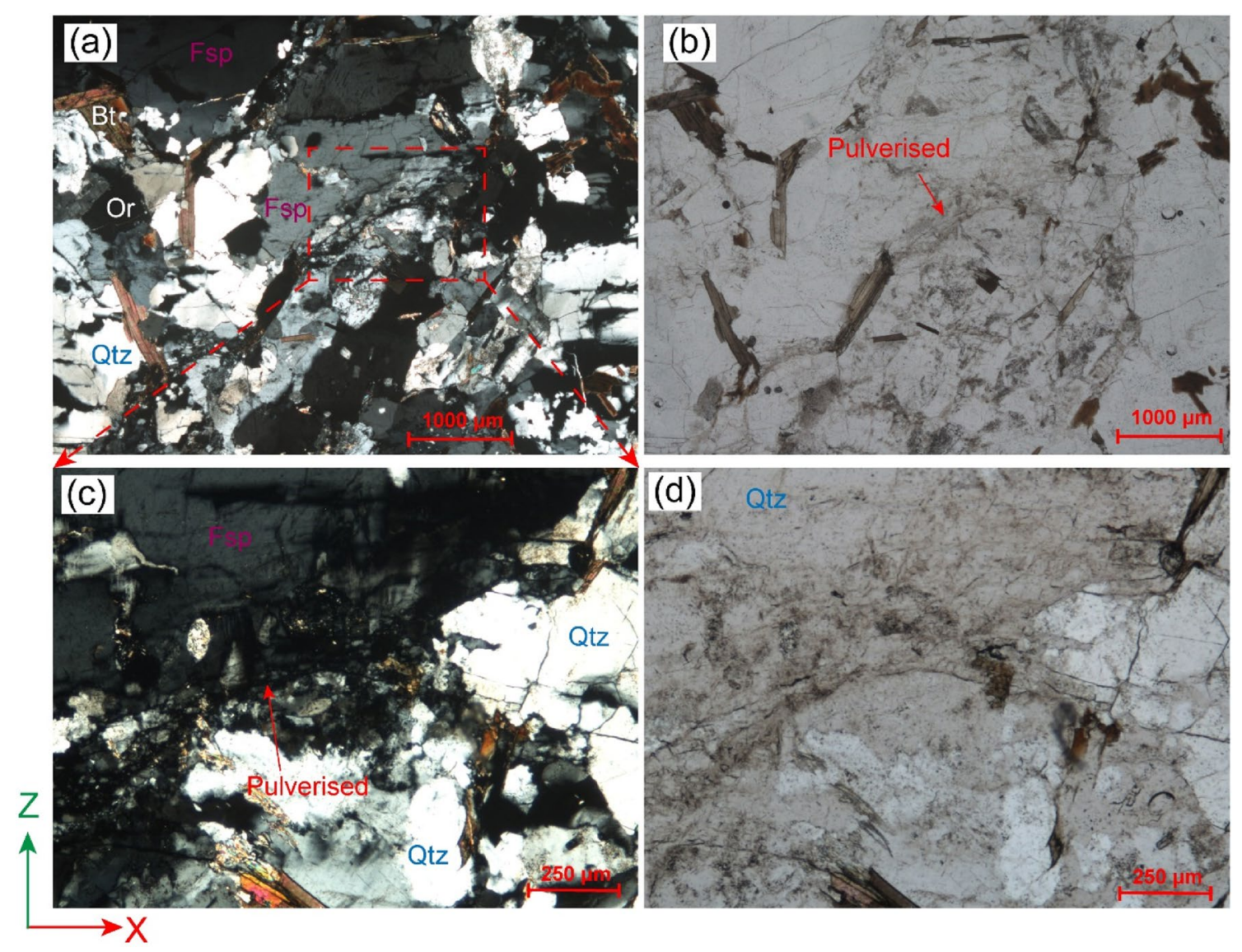

Fig. 20 Plane polarized and crossed polarized transmitted light images in the XZ plane featuring representative microstructures of granite after 10 impacts under a triaxial pre-stress state of $(30,20,10) \mathrm{MPa}$ and a repetitive velocity of $27 \mathrm{~m} / \mathrm{s}$

Rodríguez-Escudero et al. 2020; Yuan et al. 2011). Whearty et al (2017) also pointed out that the pulverized texture initiated during the dynamic rupture within the confining pressture between about 1.4 and $2.4 \mathrm{MPa}$ at shallow burial depths. Complete pulverized grains and seperated fragments are also observed along cataclastic rock fault under the confining pressure of about 10.8 MPa and with the depth of $\sim 400 \mathrm{~m}$ (Morton et al. 2012; Wechsler et al. 2009).

Figure 20a, $\mathrm{b}$ show the microscopic observations in the $\mathrm{XZ}$ section, where a main pulverized shear band is recognised across different mineral grains. The shear fracture consists of intergranular and transgranular cracks, is generally closed and filled with small forming fibrous, columnar or dendritic fragments. The closeups of grain crushing within the thin shear band are shown in Fig. 20c, d. It is clear that in situ "explosion" of grain occurs after the multiple impacts, which is the result of energy rapid accumulation and dissipation, especially under dynamic cyclic loads. The remnant crystals of grains within the shear band have a heavily altered, intergranular apperance, caused by the post shear friction.
Figure 21 shows the microscopic images in the YZ plane, where it is evident that a tensile crack generated perpendicular to the minimum principal stress direction ( $\mathrm{Z}$ direction). In this regard, the size increment of specimen in the $Z$ direction is larger than that in other two directions, similar measurements is confirmed in the decrement of ultrasonic wave velocities, as presented in Fig. 14. The tensile crack propagated across serveral grains including quarz, biotite, feldspar as well as the orthoclase, and also shows intergranular crack apperance (Fig. 21a). Under the same loading condition, the brittle minerals exbibit different deformation and failure behaviours with that of ductile ones, resulting in the uncoordinated micro-deformations and localized breakage. As zoomed in Fig. 21c, d, the brittle quartz was crushed into smaller fragments with mode I cracks while the adjacent biotite retained relaltively intact, and the major tensile crack deviated near the kinked biotites. Although the boundaries of quarz and biotite domains are generally well identified, there is a mixing of small particles across the phase boundaries due to the offset and dilation. Besides, the stepwise patterns recognized in the X-ray microtomography images (Fig. 16z) are related to the crushing of quartz (Fig. 21c). 


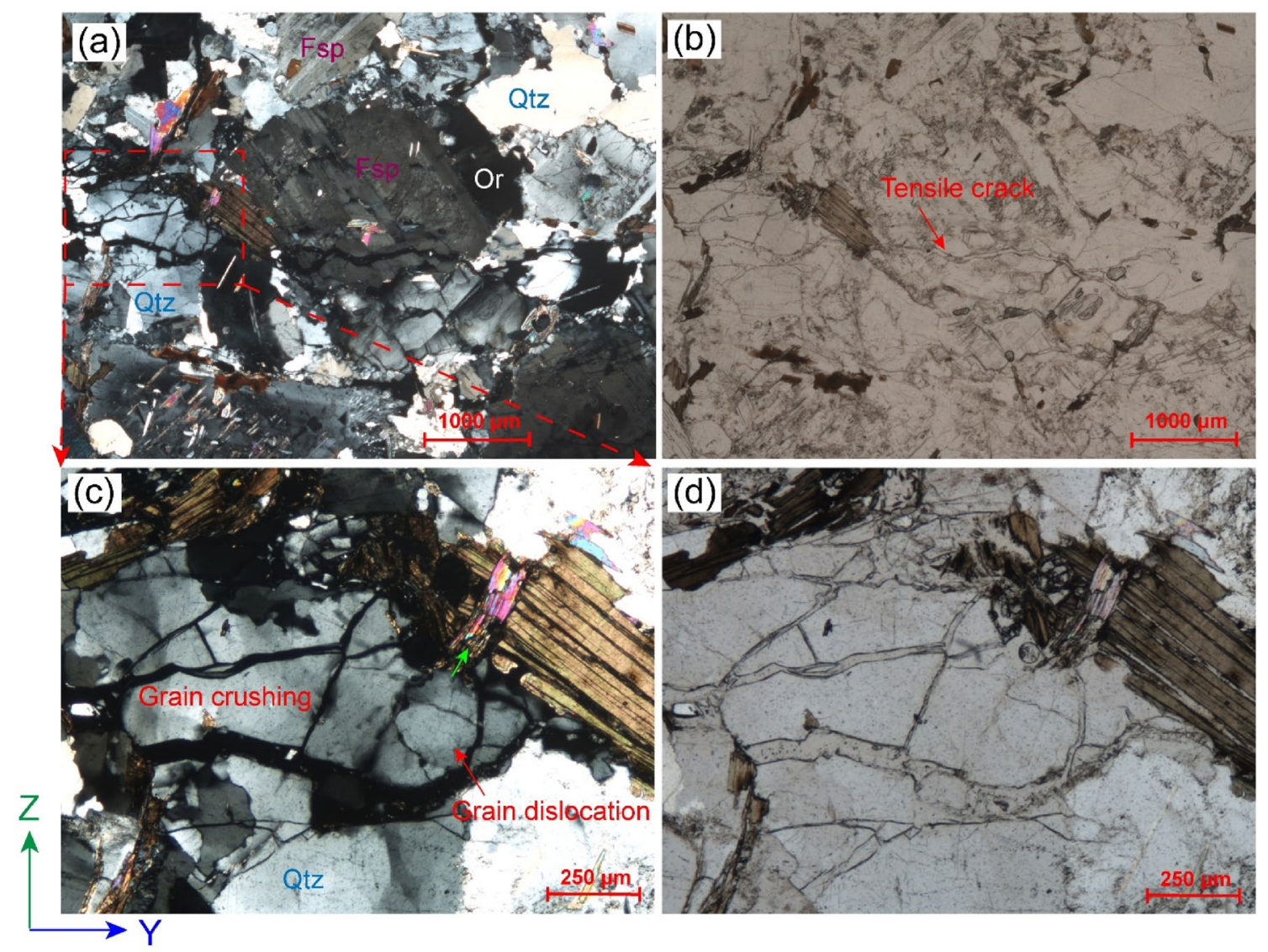

Fig. 21 Plane polarized and crossed polarized transmitted light images in the YZ plane featuring representative microstructures of granite after 10 impacts under the triaxial pre-stress state of $(30,20,10) \mathrm{MPa}$ and a repetitive imapct velocity of $27 \mathrm{~m} / \mathrm{s}$

Based on the above observation, thin section photomicrographs of the crack phenomenon thus indicate that: (1) with an inclined angle to impact direction, shear bands generate across the different grains with a large number of transgranular cracks and often filled with small dendritic fragments; (2) tensile cracks appear to propagate perpendicular to the minimum principal stress direction, and transgranular cracks predominate and dissect large grains, forming fibrous or columnar fragments that are often bounded by cleavage planes. (3) the mechanical property mismatch between different mineral phases leads to the uncoordinated micro-deformations and localised grain breakage, and the grain crushing results from the coupling effects of confining pressure and stress waves.

\subsubsection{Micro-crack Orientation, Density and Fractal Dimension}

Micro-crack orientation is another important paramteter to characterise the anisotropy of fracture networks, which is highly associated with the stress field (Moore and Lockner 1995). To measure the micro-crack orientation of granite after dynamic triaxial compression, the Directionality plugin of FIJi was used, which exploits the Local Gradients orientation method (Liu 1991; Schindelin et al. 2012). The original inputs are the crossed polarized transmitted light images (e.g. Figs. 19b, 20b, 21b) from three orthogonal directions of the granite specimen, which comprise abundant information of micro-cracks. For instance, the crossed polarized image Fig. 22a is firstly binarized and then extracted the cracks, and is shown in Fig. 22c. After the processing, the micro-cracks are well identified and presented in Fig. 22b, d. Based on that, the crack orientation is finally computed and shown in Fig. 22e, note here that $0^{\circ}$ is the East direction, and the orientation is usually counterclockwise. The amount indicates the portion of cracks in spcified orientation to the total. Moreover, using the FractalDimension plugin on the binarized thin section image, the fractal dimension of micro-cracks are computed by the box counting method. The box sizes are chosen from 640 to 6 with a reduction rate of 1.2 and 1 translations of each box. The relation between the box size and box counts is linear fitted in the bi-logarithm coordinate and thus the slope of the best fitting line is the value of fractal dimension $D$, as shown in Fig. 22f. 

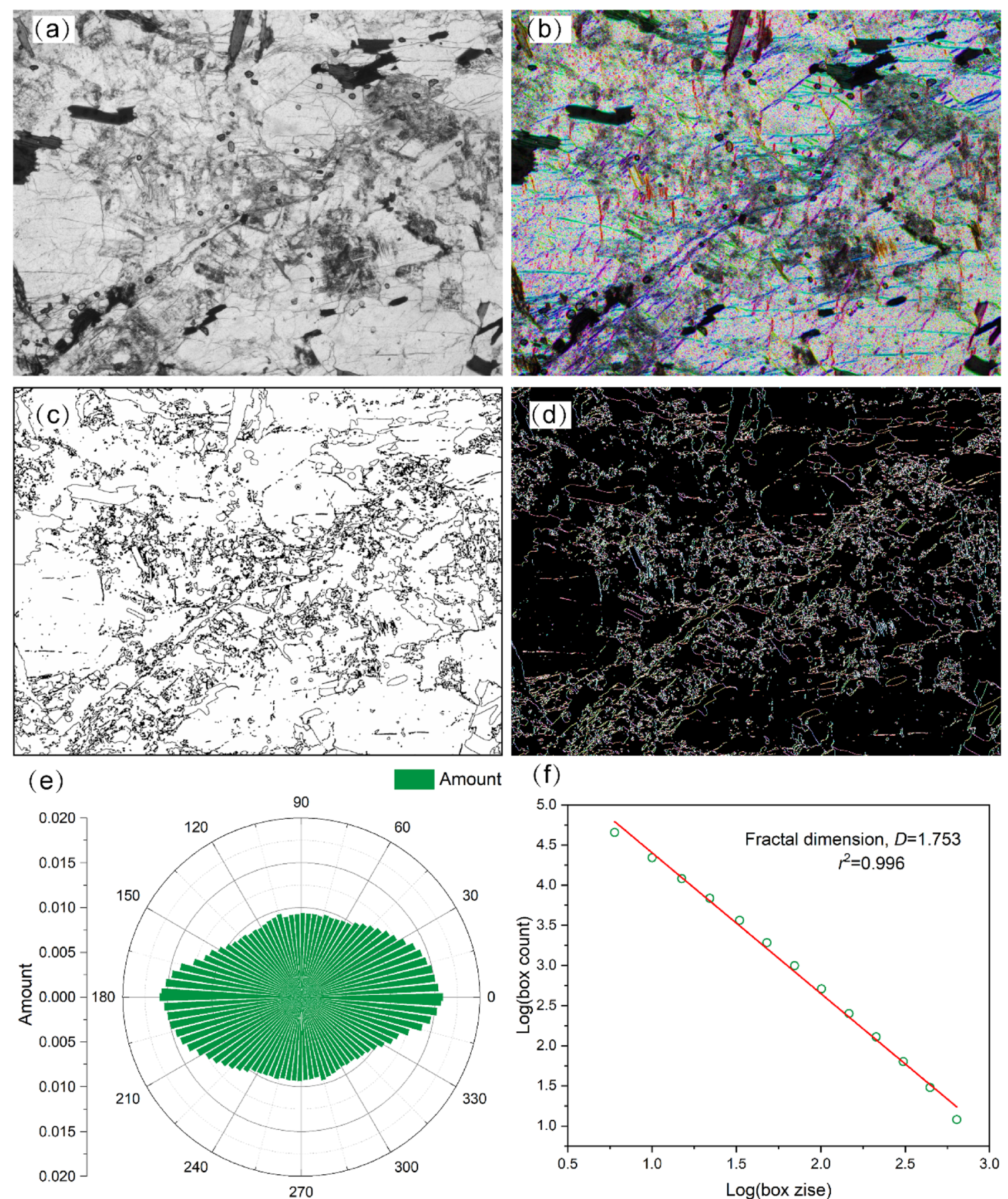

Fig. 22 Crack orientation extract from the crossed polarized section images

The rose diagrams of micro-crack directionality of granite in the $\mathrm{X}, \mathrm{Y}$ and $\mathrm{Z}$ directions are shown respectively in Fig. 18, where the induced micro-cracks by dynamic triaxial impact exhibit different peak orientations, in other words, the anisotropic micro-cracking. The peak orientation angle $A_{\text {peak }}$ of the micro-cracks in $\mathrm{XY}, \mathrm{YZ}$ and $\mathrm{XZ}$ planes are $6^{\circ}, 14^{\circ}$ and $133^{\circ}$, respectively. In the view of mechanism, the orientation distributions of micro-cracks depend on the stress state that the rock experieced during the impact. Micro-cracks appear to be preferentially parallel to the impact $X$ direction (maximum principal stress $\sigma_{1}$ ) and perpendicular to the $\mathrm{Z}$ direction (minimum principal stress $\sigma_{3}$ ).

The micro-crack desity $\rho_{\text {crack }}$, defined as the total trace lenth devided by the observed area, is calculated from the same images as for orientaition analysis. Using the AnalyzeSkeleton plugin-in Fiji, after despeckling for branches 
corresponding to single pixel, the crack densities ignoring the original are calculated and given in the Fig. 18. Crack densities in the XY, YZ and XZ planes are 1.55, 0.28 and $2.06 \mathrm{~mm} / \mathrm{mm}^{2}$, respectively. Generally, the ratio of minimum to maxinum crack density of unstressed granite, reported by Takemura and Oda (2005), is closed to 0.64-0.70. However, under dynamic triaxial compresion, the ratio of maxinum to minimum crack density of impacted granite is 7.4 , which suggests that the crack densities in three directions also show an obvious anisotropic distribution. The crack density $\rho_{\text {crack }}$ varies considerably with the observed planes and the stress states, which has been confirmed in the field observation (Whearty et al. 2017). Besides, the anisotropy of crack density is highly associated with the ultrasonic wave velocity and attenuation that discussed in Sect. 3.5.

The fractal dimension is another parameter to describe the crack complexity, related to, for example, micro-crack modes and rock micro-structures. The fractal dimension $D$ of thin sections in three directions are calculated as 1.753 , 1.758 and 1.661 and listed in Fig. 18, respectively. It seems that the fractal values of induced micro-cracks in triaxial confined rock are different in three directions, and this indicates that the effect of confinements on fractal dimensions of rock is apparent. Fractal dimension $D$ of rock is generally governed by crack propagation and branching behaviour (Heping 1989), during which the dynamic stress intensity factors and crack velocities are greatly dependent on the confining pressure.

\section{Discussion and Implication for Seismic Damage and Pulverization in Fault Zones}

The pervasive fracture textures of rock within the fault damage zones suggest that the pulverized rock forms in the strain rate sentitive domain, which can be achieved by the Hopkinson bar tests. It is clear that the pulverization strain rate threshold can be lowered by performing successive dynamic uniaxial loadings with a certain strain rate below the initial pulverization strain rate threshold (Aben et al. 2016). However, the near-fault rock in deep are commonly in triaxial pre-stress and could be pulverized when subjected to high strain rate loads. Using the triaxial Hopkinson bar, the evolution of true confining pressures, dynamic stress strain behaviour, strain rate evolution and absorbed energy of rocks under both confinement and multiple dynmaic loads are easy to capture. It is not difficult to draw that an increasing pulverization strain rate threshold with increasing confining pressure. Therefore, both of the pulverization and damage zones become thiner when going deep. Besides, the strain rates of rocks within the damage zone are non-uniform and a pre-damaged rock is easier to pulverize compared with that in the intact zone. Thus, the natural pulverized rocks may have experienced successive loadings from the subsequent seismic events, not just a single high-magnitude earthquake.

There is a clear transition from a fractured to a pulverized state in crystalline granite, while this phonomenon seems to be less obvious in the marble and sandstone. The transition from split to pulverized granite is visible in the change of ultrasonic wave characteristic, absorbed energy, crack surfacue and crack volume with increasing impact times. This difference could imply that the pulverized characteristics and mechinism vary in the different area of rock types and asymmetric distribution between bimaterial interface.

Damage anisotropy is highly ralated to the loading conditions that fault rock experienced. Microstructural analysis of crystalline granite after multiple triaxial impacts shows very similar damage textures to field observation, with the small shear offset and pervasive fragmentation below grain size. The macroscopic fracture orientation shows an inclined angle to maximum principal stress direction (impact direction), this can explain the formation of large cracks parallel to the fault during the earthquake(Bhat et al. 2007; Rempe et al. 2013).

\section{Conclusion}

Dynamic multiple impacts on three types of rock under triaxial static confinements were performed to study the progressive damage and fracture process. The triaxial pre-stress is $(30,20,10) \mathrm{MPa}$, and the repetitive impact velocity is $27 \mathrm{~m} / \mathrm{s}$ for granite and marble, or $17 \mathrm{~m} / \mathrm{s}$ for sandstone. The ultrasonic measurements, synchrotron X-ray $\mu \mathrm{CT}$ and thin sections were used to determine the damage parameters from the different views. The ultrasonic wave velocity, absorbed energy, new crack area and crack volume after each impact were quantitively determined. The main conclusions are drawn as follows:

1. The triaxial Hopkinson bar allows applying the geomaterials to the required quasi-static stress state and additional single or multiple dynamic loads, which is capable of the determination of dynamic mechanical properties under multiaxial loading conditions. During the test, the evolution of three principal stresses $\left(\sigma_{1}, \sigma_{2}\right.$ and $\left.\sigma_{3}\right)$ are synchronised and instantaneously measured from the output stress waves. The dynamic stress, dynamic strain, Young's modulus as well as energy dissipation of tested material are successfully obtained.

2. Under the triaxial pre-stress state and multiple dynamic loads, there is a critical impact time after which the dynamic stress-strain curves of rock change progressively due to the damage accumulation. During the multiple loads, both of the peak stress and Young's modulus present a decreasing tendency, while the maxi- 
mum strain, strain rate and the Poisson's ratio exhibit an increase trend with increasing impact times. With the increase of impact time, both $\mathrm{P}$ and $\mathrm{S}$ wave velocities decrease and damage values of rock increase. Besides, because of the induced micro-structure and defects, the high-frequency ultrasonic waves are filtered while the low frequency parts become dominant.

3. The X-ray $\mu \mathrm{CT}$ reveals the progressive damage and evolution of fracture networks, which involved with the micro-crack initiation, propagation, branching and coalescence. Shear bands are observed commonly in granite, and tensile cracks are prevailed for marble, while the compaction and deformation bands are the main failure mode of sandstone. In addition, the absorbed energy of rock increases with the increase of new cracks surface and volume.

4. Thin sections of granite reveal that shear bands generate across the different grains with a large number of transgranular cracks and filled with small dendritic fragments. The mechanical properties mismatch between different mineral phases leads to the uncoordinated micro-deformations and localized grain breakage. The grain crushing results from the coupling effects of confining pressure and stress waves. Besides, the microcrack orientation, density and fractal dimension show an obvious anisotropic distribution under the triaxial pre-stress state and multiple dynamic loads.

Acknowledgements This work was supported financially by the Australian Research Council (LE150100058). The first author would like to acknowledge the Australian International Postgraduate Research Scholarship and Monash Graduate Scholarship. The rock specimens are scanned by the Imaging and Medical beamline at the Australian Synchrotron (Project M14428). Special thanks to Synchrotron staff members Dr Anton Maksimenko, Dr Chris Hall and Dr Daniel Hausermann for their kind support. The authors would like to thank two anonymous reviewers for their comments that help improve the manuscript.

Open Access This article is licensed under a Creative Commons Attribution 4.0 International License, which permits use, sharing, adaptation, distribution and reproduction in any medium or format, as long as you give appropriate credit to the original author(s) and the source, provide a link to the Creative Commons licence, and indicate if changes were made. The images or other third party material in this article are included in the article's Creative Commons licence, unless indicated otherwise in a credit line to the material. If material is not included in the article's Creative Commons licence and your intended use is not permitted by statutory regulation or exceeds the permitted use, you will need to obtain permission directly from the copyright holder. To view a copy of this licence, visit http://creativecommons.org/licenses/by/4.0/.

\section{References}

Aben FM, Doan ML, Mitchell TM, Toussaint R, Reuschlé T, Fondriest M, Gratier JP, Renard F (2016) Dynamic fracturing by successive coseismic loadings leads to pulverization in active fault zones. J Geophys Res Solid Earth 121:2338-2360. https://doi.org/10.1002/ 2015JB012542

Aben FM, Doan ML, Gratier JP, Renard F (2017) Coseismic damage generation and pulverization in fault zones: insights from dynamic split-hopkinson pressure bar experiments. Fault Zone Dyn Processes Evol Fault Prop During Seismic Rupture. https://doi.org/ 10.1002/9781119156895.ch4

Aydin A (2013) Upgraded ISRM suggested method for determining sound velocity by ultrasonic pulse transmission technique. Rock Mech Rock Eng 47:255-259. https://doi.org/10.1007/ s00603-013-0454-z

Barber T, Griffith WA (2017) Experimental constraints on dynamic fragmentation as a dissipative process during seismic slip. Philos Trans A Math Phys Eng Sci. https://doi.org/10.1098/rsta.2016. 0002

Bhat HS, Dmowska R, King GC, Klinger Y, Rice JR (2007) Off-fault damage patterns due to supershear ruptures with application to the $2001 \mathrm{Mw}$ 8.1 Kokoxili (Kunlun) Tibet earthquake. J Geophys Res Solid Earth 112:B6. https://doi.org/10.1029/2006JB004425

Blair S, Cook N (1998) Analysis of compressive fracture in rock using statistical techniques: Part I. A non-linear rule-based model. Int J Rock Mech Min Sci 35:837-848. https://doi.org/10.1016/S01489062(98)00008-4

Blenkinsop TG (2007) Deformation microstructures and mechanisms in minerals and rocks. Springer, Berlin. https://doi.org/10. 1007/0-306-47543-X

Bobet A, Einstein H (1998) Fracture coalescence in rock-type materials under uniaxial and biaxial compression. Int J Rock Mech Min Sci 35:863-888. https://doi.org/10.1016/S0148-9062(98)00005-9

Bouchaud E, Bouchaud J, Fisher D, Ramanathan S, Rice J (2002) Can crack front waves explain the roughness of cracks? J Mech Phys Solids 50:1703-1725. https://doi.org/10.1016/S0022-5096(01) 00137-5

Brantut N, Heap MJ, Baud P, Meredith PG (2014) Mechanisms of timedependent deformation in porous limestone. J Geophys Res Solid Earth 119:5444-5463. https://doi.org/10.1002/2014JB011186

Braunagel MJ, Griffith WA (2019) The effect of dynamic stress cycling on the compressive strength of rocks. Geophys Res Lett 46(12):6479-6486. https://doi.org/10.1029/2019GL082723

Cai M, Kaiser P, Suorineni F, Su K (2007) A study on the dynamic behavior of the Meuse/Haute-Marne argillite. Phys Chem Earth Parts A/B/C 32:907-916. https://doi.org/10.1016/j.pce.2006.03. 007

Chaki S, Takarli M, Agbodjan W (2008) Influence of thermal damage on physical properties of a granite rock: porosity, permeability and ultrasonic wave evolutions. Constr Build Mater 22:1456-2146. https://doi.org/10.1016/j.conbuildmat.2007.04.002

Chen R, Li K, Xia K, Lin Y, Yao W, Lu F (2016) Dynamic fracture properties of rocks subjected to static pre-load using notched semi-circular bend method. Rock Mech Rock Eng 49:3865-3872. https://doi.org/10.1007/s00603-016-0958-4

Chen R, Yao W, Lu F, Xia K (2017) Evaluation of the stress equilibrium condition in axially constrained triaxial SHPB tests. Exp Mech 58:527-531. https://doi.org/10.1007/s11340-017-0344-5

Christensen RJ, Swanson SR, Brown SW (1972) Split-Hopkinson-bar tests on rock under confining pressure. Exp Mech 12:508-513. https://doi.org/10.1007/bf02320747

Cnudde V, Boone MN (2013) High-resolution X-ray computed tomography in geosciences: a review of the current technology and applications. Earth-Sci Rev 123:1-17. https://doi.org/10.1016/j. earscirev.2013.04.003

Dai F, Xia K (2010) Loading rate dependence of tensile strength anisotropy of Barre Granite. Pure Appl Geophys 167:1419-1432. https://doi.org/10.1007/s00024-010-0103-3 
Denoual C, Hild F, Cottenot C (1997) A probabilistic approach for dynamic fragmentation of ceramics under impact loading. In: ICF 9-Sydney, Australia-1997. https://doi.org/10.1016/S12518069(97)82333-0

Desrues J, Viggiani G, Besuelle P (2010) Advances in X-ray tomography for geomaterials, vol 118. Wiley, New York. https://doi.org/ $10.1002 / 9781905209606$

Doan ML, d'Hour V (2012) Effect of initial damage on rock pulverization along faults. J Struct Geol 45:113-124. https://doi.org/10. 1016/j.jsg.2012.05.006

Doan ML, Gary G (2009) Rock pulverization at high strain rate near the San Andreas fault. Nat Geosci 2:709-712. https://doi.org/10. 1038/ngeo640

Eberhardt E, Stead D, Stimpson B (1999) Quantifying progressive pre-peak brittle fracture damage in rock during uniaxial compression. Int J Rock Mech Min Sci 36:361-380. https://doi.org/ 10.1016/S0148-9062(99)00019-4

Faulkner DR, Lewis AC, Rutter EH (2003) On the internal structure and mechanics of large strike-slip fault zones: field observations of the Carboneras fault in southeastern Spain. Tectonophysics 367:235-251. https://doi.org/10.1016/S0040-1951(03)00134-3

Faulkner DR, Mitchell TM, Healy D, Heap MJ (2006) Slip on'weak'faults by the rotation of regional stress in the fracture damage zone. Nature 444:922. https://doi.org/10.1038/natur $\mathrm{e} 05353$

Fondriest M, Doan ML, Aben F, Fusseis F, Mitchell TM, Voorn M, Secco M, Toroahi GD (2017) Static versus dynamic fracturing in shallow carbonate fault zones. Earth Planet Sci Lett 461:8 19. https://doi.org/10.1016/j.eps1.2016.12.024

Freire-Lista DM, Fort R, Varas-Muriel MJ (2016) Thermal stressinduced microcracking in building granite. Eng Geol 206:8393. https://doi.org/10.1016/j.enggeo.2016.03.005

Frew DJ, Akers SA, Chen W, Green ML (2010) Development of a dynamic triaxial Kolsky bar. Meas Sci Technol 21:105704. https://doi.org/10.1088/0957-0233/21/10/105704

Ghaffari H, Griffith W, Barber T (2019) Energy delocalization during dynamic rock fragmentation. Geophys J Int 217:1034-1046. https://doi.org/10.1093/gji/ggz064

Goddard JV, Evans JP (1995) Chemical changes and fluid-rock interaction in faults of crystalline thrust sheets, northwestern Wyoming, USA. J Struct Geol 17:533-547. https://doi.org/10.1016/ 0191-8141(94)00068-B

Griffith WA, St. Julien RC, Ghaffari HO, Barber TJ (2018) A tensile origin for fault rock pulverization. J Geophys Res Solid Earth 123:7055-7073. https://doi.org/10.1029/2018JB015786

Griffiths L, Heap M, Baud P, Schmittbuhl J (2017) Quantification of microcrack characteristics and implications for stiffness and strength of granite. Int J Rock Mech Min Sci 100:138-150. https://doi.org/10.1016/j.ijrmms.2017.10.013

Homand F, Hoxha D, Belem T, Pons M-N, Hoteit N (2000) Geometric analysis of damaged microcracking in granites. Mech Mater 32:361-376. https://doi.org/10.1016/S0167-6636(00)00005-3

Hopkinson B (1914) A method of measuring the pressure produced in the detonation of high explosives or by the impact of bullets. Philos Trans R Soc A Contain Pap Math Phys Char 213:437456. https://doi.org/10.1098/rspa.1914.0008

Hu W, Liu K, Potyondy DO, Zhang Q (2020) 3D continuum-discrete coupled modelling of triaxial Hopkinson bar tests on rock under multiaxial static-dynamic loads. Int J Rock Mech Min Sci 134:104448. https://doi.org/10.1016/j.ijrmms.2020.104448

Huang Y, Ampuero JP, Helmberger DV (2014) Earthquake ruptures modulated by waves in damaged fault zones. J Geophys Res Solid Earth 119:3133-3154. https://doi.org/10.1002/2013J B010724

Incel S, Schubnel A, Renner J, John T, Labrousse L, Hilairet N, Freeman H, Wang YB, Renard F, Jamtveita B (2019) Experimental evidence for wall-rock pulverization during dynamic rupture at ultra-high pressure conditions. Earth Planet Sci Lett 528:115832. https://doi.org/10.1016/j.eps1.2019.115832

Johns RA, Steude JS, Castanier LM, Roberts PV (1993) Nondestructive measurements of fracture aperture in crystalline rock cores using X ray computed tomography. J Geophys Res Solid Earth 98:1889-1900. https://doi.org/10.1029/92JB02298

Kolsky H (1949) An investigation of the mechanical properties of materials at very high rates of loading. Proc Phys Soc 62:676. https://doi.org/10.1088/0370-1301/62/11/302/meta

Kranz RL (1979) Crack-crack and crack-pore interactions in stressed granite. Int J Rock Mech Min Sci Geomech Abstr 16(1):37-47. https://doi.org/10.1016/0148-9062(79)90773-3

Lama RD, Vutukuri VS (1978) Handbook on mechanical properties of rocks-testing techniques and results, vol 2

Li J, Ma G (2009) Experimental study of stress wave propagation across a filled rock joint. Int J Rock Mech Min Sci 46:471-478. https://doi.org/10.1016/j.ijrmms.2008.11.006

Li J, Ma G, Huang X (2010) Analysis of wave propagation through a filled rock joint. Rock Mech Rock Eng 43:789-798. https://doi. org/10.1007/s00603-009-0033-5

Li S, Zhu W, Niu L, Yu M, Chen C (2018) Dynamic characteristics of green sandstone subjected to repetitive impact loading: phenomena and mechanisms. Rock Mech Rock Eng 51:1921-1936. https://doi.org/10.1007/s00603-018-1449-6

Li X, Zhou Z, Lok T-S, Hong L, Yin T (2008) Innovative testing technique of rock subjected to coupled static and dynamic loads. Int $\mathrm{J}$ Rock Mech Min Sci 45:739-748. https://doi.org/10.1016/j.ijrmms. 2007.08.013

Li X, Zhou Z, Zhao F, Zuo Y, Ma C, Ye Z, Hong L (2009) Mechanical properties of rock under coupled static-dynamic loads. Int $\mathbf{J}$ Rock Mech Min Sci 1:41-47. https://doi.org/10.3724/sp.J.1235. 2009.00041

Li XB, Lok TS, Zhao J (2004) Dynamic characteristics of granite subjected to intermediate loading rate. Rock Mech Rock Eng 38:2139. https://doi.org/10.1007/s00603-004-0030-7

Lindholm US, Yeakley LM, Nagy A (1972) A study of the dynamic strength and fracture properties of rock. Southwest Res Inst San Antonio Tx, 1972.

Liu K, Zhang QB, Zhao J (2018) Dynamic increase factors of rock strength. Rock dynamics: experiments, theories and applications: proceedings of the $3 \mathrm{rd}$ international conference on rock dynamics and applications (RocDyn-3). CRC Press, p 169

Liu K, Zhang Q (2019) Dynamic behaviors of sandstone under true tri-axial confinements: tri-axial hopkinson bar tests. In: 53rd US Rock Mechanics/Geomechanics Symposium. New York: American Rock Mechanics Association; 2019: 23-26. June.

Liu K, Zhang Q, Wu G, Li J, Zhao J (2019) Dynamic mechanical and fracture behaviour of sandstone under multiaxial loads using a triaxial hopkinson bar. Rock Mech Rock Eng 52(7):2175-2195. https://doi.org/10.1007/s00603-018-1691-y

Liu K, Zhao J, Wu G, Maksimenko A, Haque A, Zhang Q (2020a) Dynamic strength and failure modes of sandstone under biaxial compression. Int J Rock Mech Min Sci 128:104260. https://doi. org/10.1016/j.ijrmms.2020.104260

Liu P, Liu K, Zhang Q-B (2020b) Experimental characterisation of mechanical behaviour of concrete-like materials under multiaxial confinement and high strain rate. Constr Build Mater 258:119638. https://doi.org/10.1016/j.conbuildmat.2020.119638

Liu Z-Q (1991) Scale space approach to directional analysis of images. Appl Opt 30:1369-1373. https://doi.org/10.1364/AO.30.001369

Lundberg B (1976) A split Hopkinson bar study of energy absorption in dynamic rock fragmentation. Int J Rock Mech Min Sci Geomech Abstr 13(6):187-197. https://doi.org/10.1016/01489062(76)91285-7 
Luo X, Jiang N, Wang M, Xu Y (2016) Response of leptynite subjected to repeated impact loading. Rock Mech Rock Eng 49:4137-4141. https://doi.org/10.1007/s00603-015-0896-6

Ma M, Brady B (1999) Analysis of the dynamic performance of an underground excavation in jointed rock under repeated seismic loading. Geotech Geol Eng 17:1-20. https://doi.org/10.1023/A: 1008864329747

Mitchell T, Ben-Zion Y, Shimamoto T (2011) Pulverized fault rocks and damage asymmetry along the Arima-Takatsuki Tectonic Line, Japan. Earth Planet Sci Lett 308:284-297. https://doi.org/ 10.1016/j.epsl.2011.04.023

Mitchell T, Faulkner D (2009) The nature and origin of off-fault damage surrounding strike-slip fault zones with a wide range of displacements: a field study from the Atacama fault system, northern Chile. J Struct Geol 31:802-816. https://doi.org/10.1016/j. jsg.2009.05.002

Mitchell TM et al (2017) Fluid inclusion evidence of coseismic fluid flow induced by dynamic rupture. Fault Zone Dyn Processes Evol Fault Prop During Seismic Rupture. https://doi.org/10.1002/97811 19156895.ch3

Moore DE, Lockner D (1995) The role of microcracking in shear-fracture propagation in granite. J Struct Geol 17(1):95-114. https:// doi.org/10.1016/0191-8141(94)E0018-T

Morton N, Girty GH, Rockwell TK (2012) Fault zone architecture of the San Jacinto fault zone in Horse Canyon, southern California: a model for focused post-seismic fluid flow and heat transfer in the shallow crust. Earth Planet Sci Lett 329:71-83. https://doi.org/ 10.1016/j.epsl.2012.02.013

Nasseri M, Rezanezhad F, Young R (2011) Analysis of fracture damage zone in anisotropic granitic rock using 3D X-ray CT scanning techniques. Int J Fract 168:1-13. https://doi.org/10.1007/ s10704-010-9551-0

Olsson W (1991) The compressive strength of tuff as a function of strain rate from $10^{-6}$ to $10^{3} / \mathrm{sec}$. Int J Rock Mech Min Sci Geomech Abstr 1:115-118. https://doi.org/10.1016/01489062(91)93241-W

Ramesh KT (2008) High rates and impact experiments. In: Sharpe WN (ed) Springer handbook of experimental solid mechanics. Springer, Boston, pp 929-960. https://doi.org/10.1007/978-0-38730877-7_33

Ramulu M, Chakraborty A, Sitharam T (2009) Damage assessment of basaltic rock mass due to repeated blasting in a railway tunnelling project—a case study. Tunn Undergr Sp Technol 24:208-221. https://doi.org/10.1016/j.tust.2008.08.002

Ravi-Chandar K, Knauss W (1984) An experimental investigation into dynamic fracture: II. Microstructural aspects. Int J Fract 26:6580. https://doi.org/10.1007/BF01152313

Rempe M, Mitchell T, Renner J, Nippress S, Ben-Zion Y, Rockwell T (2013) Damage and seismic velocity structure of pulverized rocks near the San Andreas Fault. J Geophys Res Solid Earth 118:2813-2831. https://doi.org/10.1002/jgrb.50184

Renard F, Bernard D, Desrues J, Ougier-Simonin A (2009) 3D imaging of fracture propagation using synchrotron X-ray microtomography. Earth Planet Sci Lett 286:285-291. https://doi.org/10.1016/j. eps1.2009.06.040

Rockwell T, Sisk M, Girty G, Dor O, Wechsler N, Ben-Zion Y (2009) Chemical and physical characteristics of pulverized Tejon Lookout Granite adjacent to the San Andreas and Garlock faults: implications for earthquake physics. Pure Appl Geophys 166:17251746. https://doi.org/10.1007/s00024-009-0514-1

Rodríguez-Escudero E, Martínez-Díaz JJ, Giner-Robles JL, Tsige M, Cuevas-Rodríguez J (2020) Pulverized quartz clasts in gouge of the Alhama de Murcia fault (Spain): evidence for coseismic clast pulverization in a matrix deformed by frictional sliding. Geology 48:283-287. https://doi.org/10.1130/G47007.1
Rummel F, Vanheerden W (1978) Suggested methods for determining sound-velocity. Int J Rock Mech Min Sci 15:53-58. https://doi. org/10.1016/0148-9062(78)91678-9

Santos C, Urdaneta V, Jaimes G, Trujillo L (2010) Ultrasonic spectral and complexity measurements on brine and oil saturated rocks. Rock Mech Rock Eng 43:351-359. https://doi.org/10.1007/ s00603-009-0047-z

Schindelin J et al (2012) Fiji: an open-source platform for biologicalimage analysis. Nat Methods 9(7):676-682. https://doi.org/10. 1038/nmeth.2019

Takemura T, Oda M (2005) Changes in crack density and wave velocity in association with crack growth in triaxial tests of Inada granite. J Geophys Res Solid Earth 110:B05401. https://doi.org/10.1029/ 2004JB003395

Tapponnier P, Brace W (1976) Development of stress-induced microcracks in Westerly granite. Int J Rock Mech Min Sci Geomech Abstr 4:103-112. https://doi.org/10.1016/0148-9062(76)91937-9

Tong L, Yu Y, Lai S, Lim C (2019) Dynamic weakening of sandstone subjected to repetitive impact loading. Rock Mech Rock Eng 52:2197-2206. https://doi.org/10.1007/s00603-018-1713-9

Vicente MA, Mínguez J, González DC (2017) The use of computed tomography to explore the microstructure of materials in civil engineering: from rocks to concrete. Computed tomographyadvanced applications. InTech, Rejika

Wechsler N, Allen E, Rockwell T, Chester J, Ben-Zion Y (2009) Characterization of pulverized granite from a traverse and a shallow drill along the San Andreas fault, Little Rock, CA. In: Seismological Society of America Annual Meeting, Seismol Res Lett, p 319

Whearty JJ, Rockwell TK, Girty GH (2017) Incipient pulverization at shallow burial depths along the San Jacinto Fault, Southern California Fault Zone. Dyn Processes Evol Fault Prop During Seismic Rupture 227:1. https://doi.org/10.1002/9781119156895.ch1

Wilson B, Dewers T, Ze R, Brune J (2005) Particle size and energetics of gouge from earthquake rupture zones. Nature 434:749-752. https://doi.org/10.1038/nature03433

Wu B, Kanopoulos P, Luo X, Xia K (2014) An experimental method to quantify the impact fatigue behavior of rocks. Meas Sci Technol 25(7):075002. https://doi.org/10.1088/0957-0233/25/7/075002

Wu B, Yao W, Xia K (2016) An experimental study of dynamic tensile failure of rocks subjected to hydrostatic confinement. Rock Mech Rock Eng 49:3855-3864. https://doi.org/10.1007/ s00603-016-0946-8

Wu XY, Baud P, Wong T-f (2000) Micromechanics of compressive failure and spatial evolution of anisotropic damage in Darley Dale sandstone. Int J Rock Mech Min Sci 37:143-160. https://doi.org/ 10.1016/S1365-1609(99)00093-3

Xia K, Nasseri MHB, Mohanty B, Lu F, Chen R, Luo SN (2008) Effects of microstructures on dynamic compression of Barre granite. Int J Rock Mech Min Sci 45:879-887. https://doi.org/10. 1016/j.ijrmms.2007.09.013

Xie H (1989) The fractal effect of irregularity of crack branching on the fracture toughness of brittle materials. Int J Fract 41:267-274. https://doi.org/10.1007/BF00018858

Xu S, Ben-Zion Y (2017) Theoretical constraints on dynamic pulverization of fault zone rocks. Geophys J Int 209:282-296. https://doi. org/10.1093/gji/ggx033

Xu Y, Yao W, Xia K, Ghaffari HO (2019) Experimental study of the dynamic shear response of rocks using a modified punch shear method. Rock Mech Rock Eng 52:2523-2534. https://doi.org/10. 1007/s00603-019-1744-x

Xu S, Shan J, Zhang L, Zhou L, Gao G, Hu S, Wang P (2020) Dynamic compression behaviors of concrete under true triaxial confinement: an experimental technique. Mech Mater 140:103220. https://doi.org/10.1016/j.mechmat.2019.103220 
Yuan F, Prakash V, Tullis T (2011) Origin of pulverized rocks during earthquake fault rupture. J Geophys Res Solid Earth 116:B06309. https://doi.org/10.1029/2010jb007721

Zhang QB, Zhao J (2014a) Quasi-static and dynamic fracture behaviour of rock materials: phenomena and mechanisms. Int J Fract 189:1-32. https://doi.org/10.1007/s10704-014-9959-z

Zhang QB, Zhao J (2014b) A review of dynamic experimental techniques and mechanical behaviour of rock materials. Rock Mech Rock Eng 47:1411-1478. https://doi.org/10.1007/ s00603-013-0463-y

Zhao D, Huang Z, Umino N, Hasegawa A, Kanamori H (2011) Structural heterogeneity in the megathrust zone and mechanism of the 2011 Tohoku-oki earthquake (Mw 9.0). Geophys Res Lett 38:L17308. https://doi.org/10.1029/2011GL048408

Zhou YX et al (2012) Suggested methods for determining the dynamic strength parameters and mode-I fracture toughness of rock materials. Int J Rock Mech Min Sci 49:105-112. https://doi.org/10. 1016/j.ijrmms.2011.10.004

Zhou Z, Li X, Zou Y, Jiang Y, Li G (2014) Dynamic Brazilian tests of granite under coupled static and dynamic loads. Rock Mech Rock Eng 47:495-505. https://doi.org/10.1007/s00603-013-0441-4
Zhu J, Zhou T, Liao Z, Sun L, Li X, Chen R (2018) Replication of internal defects and investigation of mechanical and fracture behaviour of rock using 3D printing and 3D numerical methods in combination with X-ray computerized tomography. Int J Rock Mech Min Sci 106:198-212. https://doi.org/10.1016/j.ijrmms. 2018.04.022

Zhu W, Bai Y, Li X, Niu L (2012) Numerical simulation on rock failure under combined static and dynamic loading during SHPB tests. Int J Impact Eng 49:142-157. https://doi.org/10.1016/j.ijimpeng. 2012.04.002

Zhu W, Niu L, Li S, Xu Z (2015) Dynamic Brazilian test of rock under intermediate strain rate: pendulum hammer-driven SHPB test and numerical simulation. Rock Mech Rock Eng 48:1867-1881. https://doi.org/10.1007/s00603-014-0677-7

Publisher's Note Springer Nature remains neutral with regard to jurisdictional claims in published maps and institutional affiliations. 